\title{
Modeling of Loess Soaking Induced Impacts on a Metro Tunnel Using a Water Soaking System in Centrifuge
}

\author{
Yuwei Zhang $\mathbb{D}^{1,2}$ Xiaolin Weng $\mathbb{D}^{3},{ }^{3}$ Zhanping Song $\mathbb{D}^{1,2}$ and Yufeng Sun $^{3}$ \\ ${ }^{1}$ School of Civil Engineering, Xi'an University of Architecture and Technology, Xi'an 710055, China \\ ${ }^{2}$ Shaanxi Key Laboratory of Geotechnical and Underground Space, Xi'an University of Architecture and Technology, \\ Xi'an 710055, China \\ ${ }^{3}$ School of Highway, Chang'an University, Xi'an 710064, China
}

Correspondence should be addressed to Yuwei Zhang; 1032659676@qq.com and Zhanping Song; songzhpyt@xauat.edu.cn Received 23 August 2018; Revised 27 November 2018; Accepted 1 January 2019; Published 9 May 2019

Academic Editor: Constantinos Loupasakis

Copyright (c) 2019 Yuwei Zhang et al. This is an open access article distributed under the Creative Commons Attribution License, which permits unrestricted use, distribution, and reproduction in any medium, provided the original work is properly cited.

\begin{abstract}
The collapsibility is one of the key properties for loess. Harmful impacts on the metro tunnels could be obviously subjected to the soaking collapsibility in collapsible loess. However, loess soaking cannot be effectively modeled by the existing centrifugal test equipment (CTE) due to its inherent limitations. In the present paper, a water soaking system (WSS) was improved based on the existing CTE for simulating various loess soaking conditions. The WSS was made of a water storage subsystem and a water distribution subsystem. Some tests were conducted to show the capability of the improved WSS in centrifugal model tests firstly, then it was used to carry out centrifugal model tests on a metro tunnel under full-range and half-range foundation soaking conditions with different soaking depths. The impacts of various soaking conditions on the mechanical properties of the metro tunnel were discussed in detail.
\end{abstract}

\section{Introduction}

As a part of the city transport line, the metro tunnel is becoming increasingly more important which can take full advantage of the underground space. Underground water level may change due to a large number of underground constructions. For metro tunnels, foundation soaking may cause such serious diseases as differential settlement and lining cracks in tunnel structures in collapsible loess $[1,2]$. Collapsible loess is widely distributed in Xi'an city of China. Many sections of the three existing metro lines and some anticipated metro lines are located in the collapsible loess area [3-11]. Hence, it is with great significance to investigate the influence of collapsibility induced by foundation soaking on the mechanical properties of the metro tunnel and determine a reasonable foundation noncollapsible depth that could provide guidance for metro tunnel construction [12-16]. The centrifugal model test is a proven approach and has been widely applied in the field of geotechnical engineering testing. In the early stage, Schofield used a centrifuge to analyze geotechnical problems [17-27], then the centrifuge tests were gradually applied to all aspects of geotechnical engineering [18-23]. Also, the centrifuge was used for tunnel analysis [24-26]. The true stress conditions of a metro tunnel can be modeled by adjusting the centrifugal acceleration [27]. However, different collapsible conditions of the metro tunnel caused by foundation soaking cannot be well simulated in the currently CTE [21, 28-31] due to its inherent limitations. Till date, to simulate the water soaking, the machine-halt method has usually been used, but there exist differences with the actual conditions for some parameters such as the moisture migration pattern, the water rate control, and the method of soaking $[20,32,33]$. So the currently soaking method used in CTE could not well reproduce the actual foundation soaking condition, and very few studies have been carried out successfully to investigate the influence of foundation soaking on the metro tunnel by centrifugal model tests. Therefore, it is necessary to develop the CTE and find a more effective soaking method to satisfy the requirements of various conditions of foundation soaking testing. 


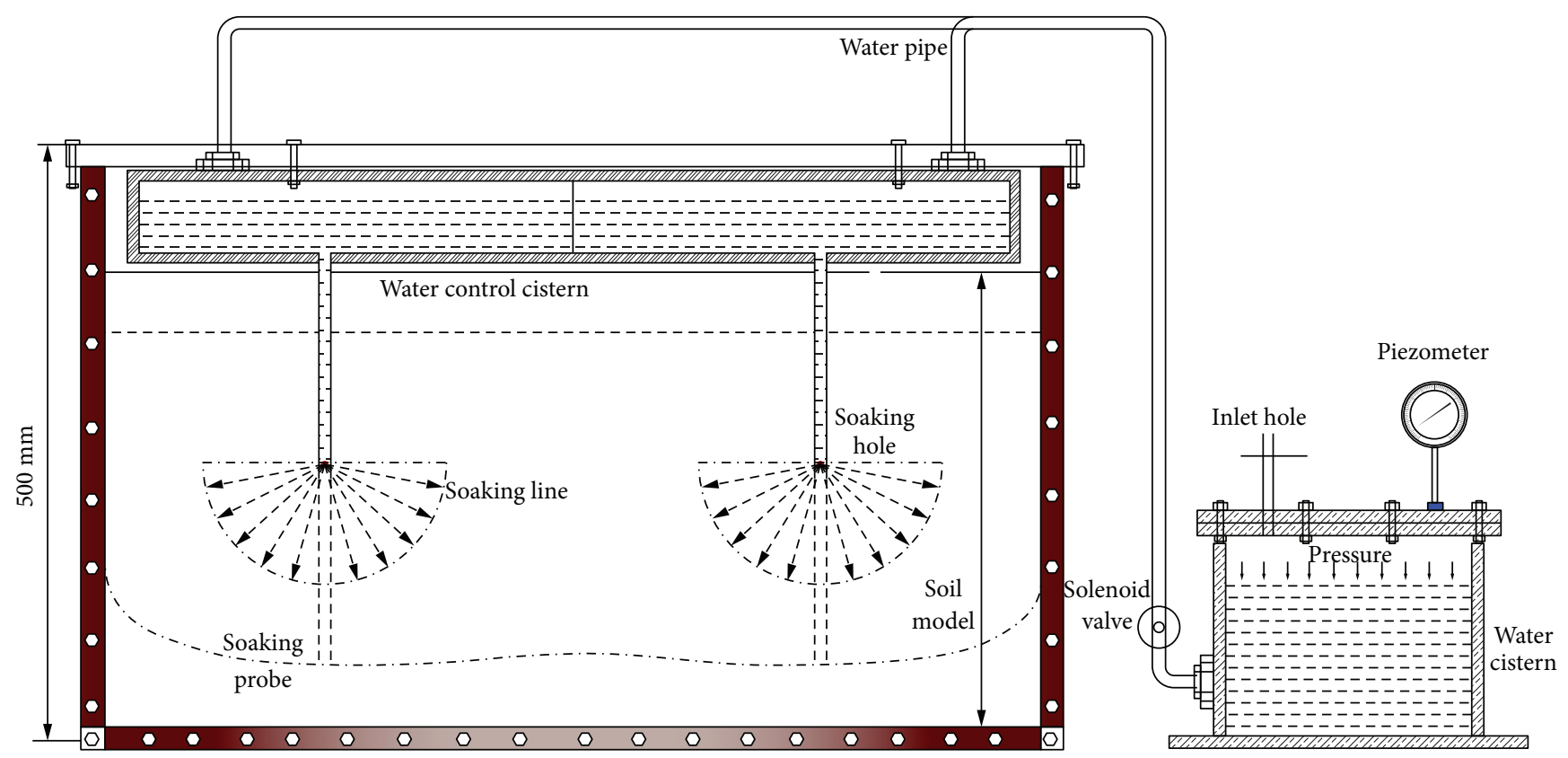

FIGURE 1: Design of water soaking system (WSS).

In the past decades, there have been several improvements in CTE for simulation of different testing conditions [34], which, however, were mainly in the field of landslides, aiming at analysis of rainfall-related stability of landslides [35-45]. To the best of the authors' knowledge, the improvement of WSS for foundation soaking in metro tunnels has not been reported so far, and therefore, research on the influence of different foundation soaking conditions on metro tunnel was rarely conducted, and investigations on foundation soaking by centrifugal model tests are hardly seen. For the reasons mentioned above, a WSS for tunnel was improved based on CTE and a more effective method of water soaking was introduced in the present study. Some tests were conducted to show the capability of the improved WSS in centrifugal model tests firstly, then a series of centrifugal model tests related to half-range and full-range foundation soaking with different soaking depths were conducted and the influence of different foundation soaking conditions on the mechanical properties of the metro tunnel was discussed systematically.

\section{Improvement of WSS}

2.1. Introduction of CTE. The WSS was improved based on the centrifugal testing equipment TLJ-3 in Chang'an University. It has a maximum capacity of $60 \mathrm{~g}$-ton, an effective radius of $2 \mathrm{~m}$, and a range of acceleration from $1 \mathrm{~g}$ to $200 \mathrm{~g}$, and there are two model boxes with the dimensions of $700 \mathrm{~mm} \times 360 \mathrm{~mm} \times 500 \mathrm{~mm}$ and $500 \mathrm{~mm} \times 360 \mathrm{~mm} \times$ $400 \mathrm{~mm}$, respectively. The requirement of conventional geotechnical tests could be satisfied by the current CTE [3]. There are two main ways for data acquisition: sensor acquisition and image capture acquisition. The first acquisition could be equipped with sensors such as soil pressure boxes, strain gauges, and laser displacement sensors as required, and the later one consists of an HD camera, a video camera, and the corresponding control system with the results obtained from image processing software. The sensor acquisition system has been mainly adopted in this study.

2.2. Design of WSS. The improved WSS is made up of two subsystems: the water storage subsystem and the water distribution subsystem. The former system has the function of water storage and conveyance, and the latter, controlled by solenoid valves, could make the soaking effect of each soaking point more uniform. The design of the WSS is shown in Figure 1. It is shown that the water storage subsystem includes a water cistern, water pipes, solenoid values, etc. The water cistern is made of a $3 \mathrm{~mm}$-thick stainless steel plate, which could be fixed on the centrifugal arm. The water distribution subsystem consists of a water control cistern and four soaking probes. Furthermore, there are four compartments in the water control cistern, each of which is connected to a single water pipe. The water pipe, controlled by the solenoid value, connects the water cistern and the water control cistern. The soaking probe, with four holes at its lower end, is fixed at the bottom of the water control cistern, and the diameter is $1 \mathrm{~cm}$. The length of the soaking probe could be adjusted to adapt to different conditions. Before the test, the device should be installed as shown in Figure 1 and be debugged to bring it to proper working condition.

2.3. Water Soaking Control Program. When the saturation of undisturbed loess reaches $85 \%$, it is considered to be in a saturated collapsible state $[3,21,25]$. Thus, the storage capacity in the water cistern could be calculated in advance depending on the dosage of the model soil. Further, to achieve a better effect of soaking, $110 \%$ of calculation water storage is used in tests. Before the water soaking progresses, the centrifuge is operated at a given acceleration and kept stable for a minute. The progress of water soaking is controlled by the 


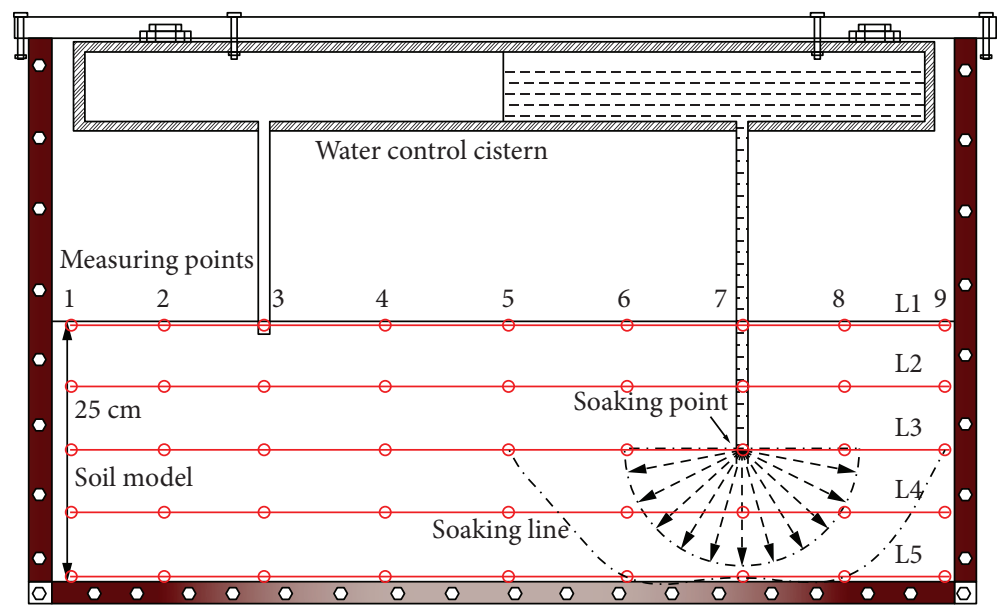

(a) Half-range soaking

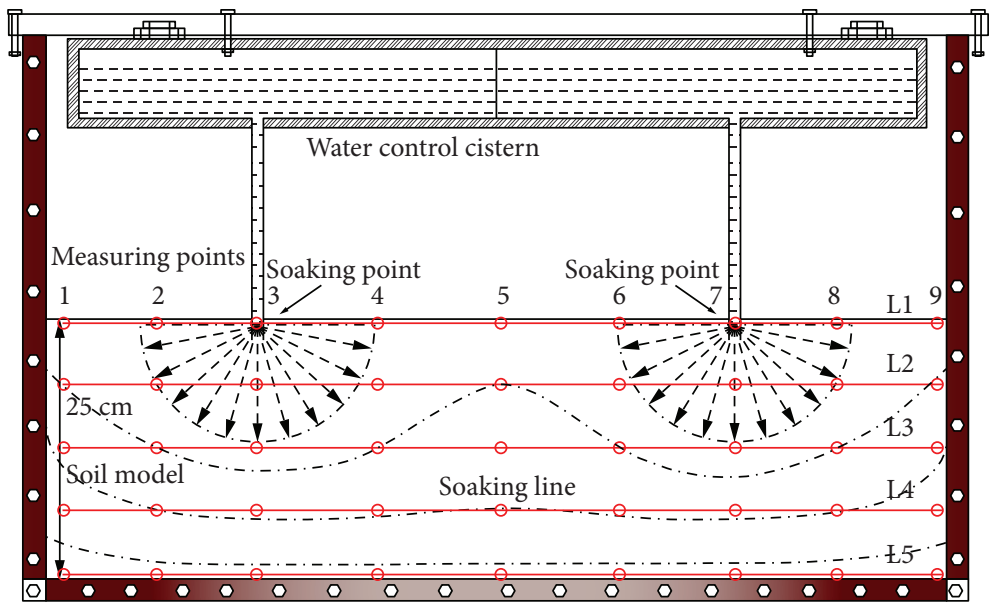

(b) Full-range soaking

Figure 2: Design scheme of soaking tests.

solenoid valve fixed on the water pipe, to ensure that the moisture migrates uniformly in the model soil under the effect of centrifugal force, and the model loess could reach the saturated collapsible state; the solenoid was switched through long-distance automatic control, and the progress of water soaking during the centrifugal operation can be controlled according to the testing progress. In addition, each solenoid valve could be switched due to the requirements of each soaking point which can improve the accuracy of the water soaking in each soaking point and ensure the satisfaction of the soaking conditions.

2.4. Validation of Water Soaking Effect. In this section, the effect of water soaking of the improved WSS was verified for loess. The effect of water soaking was evaluated by water content in each measuring point. If the water content was over $28 \%$, the loess began to collapsible. The target water content for both the half-range and full-range models was $28 \%$. Several soaking tests were conducted, and the design scheme is shown in Figure 2. Half-range soaking is modeled at first in which the soaking probe was placed in the middle of the loess layer, and then full-range soaking is considered where the soaking probes were placed at the top of the loess layer at some points to measure the moisture content. To verify the effect of soaking in the simplest testing procedure, the remolded loess was used in the tests, and the other parameters are as follows: the original moisture content of the remolded loess was $16.7 \%$, the original void ratio was 1.16 , and the depth of the loess layer was $25 \mathrm{~cm}$. As the currently used instruments for measuring moisture content are too big to be used in the centrifugal model tests, the moisture content at each point was measured using the oven drying method after the completion of the centrifugal operation. The results for half-range soaking and full-range soaking tests are shown in Figures 3 and 4, respectively.

It can be seen from Figure 3 that a better soaking effect is observed for the soil under the soaking probe, and the moisture content at the soaking point reached 33.6\%. Moreover, the soaking effect becomes gradually weakened with the horizontal distance, and the moisture content at point 1 in L5 was $17.1 \%$. Thus, the soil under the soaking probe could satisfy the requirement of collapsibility. However, the soaking effect above the soaking probe was not so good, with the moisture contents at the soaking points in L1 and L2 being $19.6 \%$ and $21.7 \%$, respectively. The reason is that, under the influence of centrifugal force, the moisture in the 


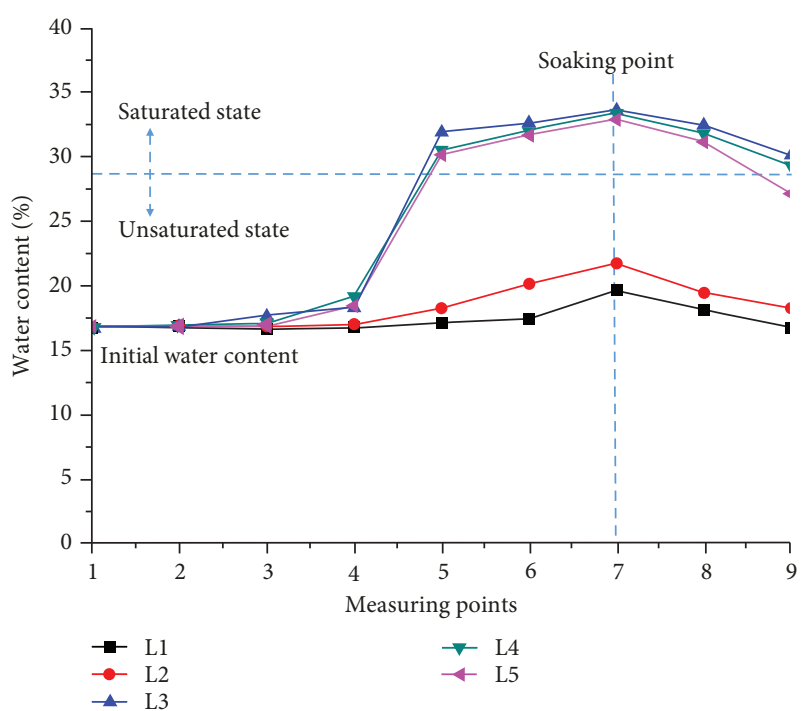

FIgURE 3: Results for half-range soaking.

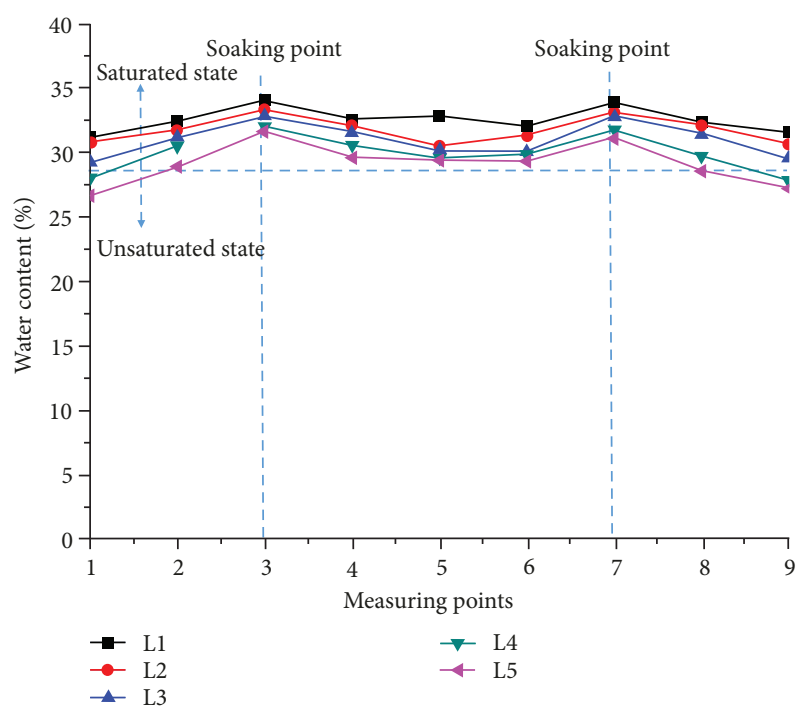

FIGURE 4: Results for full-range soaking.

soil tends to migrate along the centrifugal force direction. Therefore, the WSS is satisfied for half-range soaking by placing the probe at the top of the loess layer. It can be seen from Figure 4 that the moisture content at the two soaking points were $34.1 \%$ and $33.9 \%$, respectively, and that the soaking effect becomes gradually weakened along the horizontal distance and vertical distance. The moisture contents at point 1 and point 9 in L5 were $26.7 \%$ and $27.3 \%$, respectively, and the moisture content at point 5 in the middle position was $29.5 \%$. The WSS is also satisfied for the full-range soaking.

\section{Foundation Soaking Tests Using WSS}

3.1. Model Material. To study the influence of foundation soaking collapsibility on metro tunnel structures, the improved WSS was used to conduct centrifugal model tests under different foundation soaking conditions. All the model

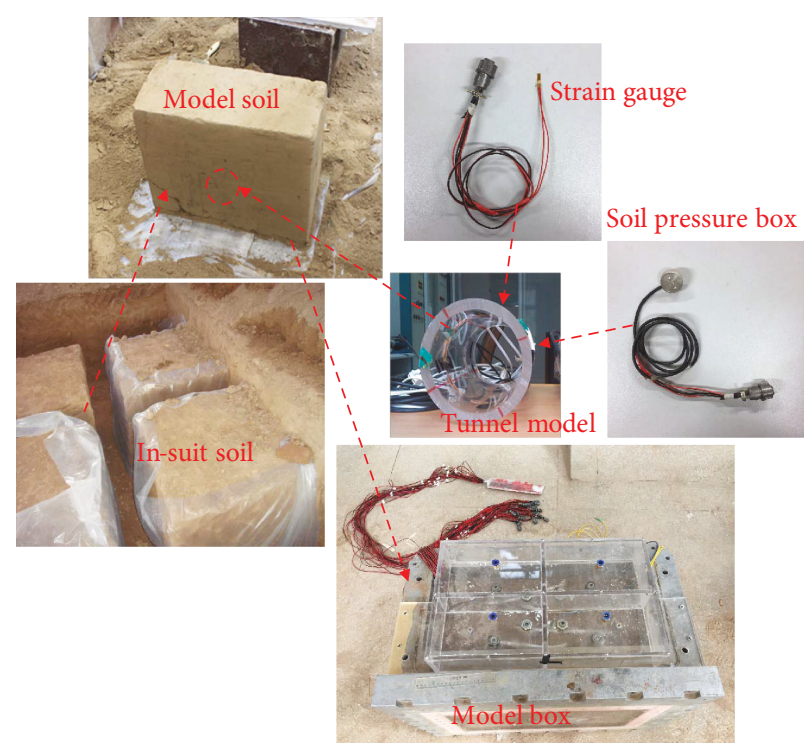

Figure 5: Experimental process photos.

soils used were original loess taken from Hongqing station construction site in Xi'an with the following parameters: the degree of self-weight collapsibility of the loess was IV [3], the depth of the samples was varying from $14.7 \mathrm{~m}$ to $22.5 \mathrm{~m}$, and the average coefficient of self-weight collapsibility was 0.045 . The degree of self-weight collapsibility was used for evaluating the collapsibility of the loess layer, and it could be determined by the self-weight collapsibility value and the collapsibility value. The self-weight collapsibility value could be calculated by the coefficient of self-weight collapsibility, which is the testing value of the self-weight collapsibility test. The soil is undisturbed loess, and the structural characteristics and the moisture content were kept as per the original levels. The soil model was made as per the designed size, with $700 \mathrm{~mm}$ (length) $\times 360 \mathrm{~mm}$ (width) $\times$ $500 \mathrm{~mm}$ (height) (shown in Figure 5). The main soil parameters are listed in Table 1. Dry silver sand with relative compactness $\mathrm{Dr}=0.78$ was placed between the model soil and the model box to decrease the errors caused by the cracking.

In this study, more attention was paid to the influence of different foundation soaking conditions on the mechanical characteristics of the metro tunnel. The effect of construction progress of the metro tunnel was ignored, and therefore, the tunnel model was made of organic glass in advance, with an elastic modulus of $6 \mathrm{GPa}$, a Poisson ratio of 0.3 , a diameter of $100 \mathrm{~mm}$, and a thickness of $10 \mathrm{~mm}$. The tunnel model is also shown in Figure 5. The preparation of the model is as follows. Firstly, a hole for the tunnel model was excavated in the soil model and then the tunnel was pushed into the hole with the gap between them filled by fine sand. At the same time, soil pressure boxes and strain gauges were installed at the designed measuring points. Secondly, the soil model was placed into the model box, and the WSS was installed (shown in Figure 6). The right amount of water calculated by the soaking depth was put into the cistern, and opening the switch of water control cistern after the centrifuge runs stable. The data was recorded from the beginning to the end of water immersion. Before the tests, all the sensors such as 
TABle 1: Parameters of model soil.

\begin{tabular}{lccccc}
\hline $\begin{array}{l}\text { Natural } \\
\text { gravity }\end{array}$ & $\begin{array}{c}\text { Water } \\
\text { content }\end{array}$ & $\begin{array}{c}\text { Void } \\
\text { ratio }\end{array}$ & $\begin{array}{c}\text { Modulus of } \\
\text { compressibility }\end{array}$ & $\begin{array}{c}\text { Cohesive } \\
\text { strength }\end{array}$ & $\begin{array}{c}\text { Internal } \\
\text { friction } \\
\text { angle }\end{array}$ \\
\hline $15.1 \mathrm{kN} / \mathrm{m}^{3}$ & $16.7 \%$ & 1.16 & $12.6 \mathrm{MPa}$ & $27 \mathrm{kPa}$ & $19^{\circ}$ \\
\hline
\end{tabular}

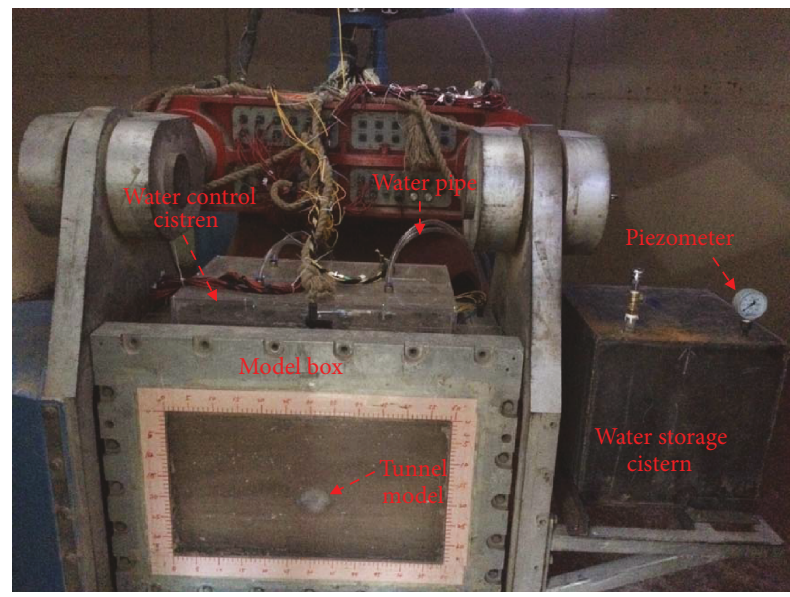

Figure 6: Model installation.

TABle 2: Centrifugal scaling laws.

\begin{tabular}{lcc}
\hline Parameter & Unit & $\begin{array}{c}\text { Scaling ratio } \\
\text { (model/prototype) }\end{array}$ \\
\hline Gravitational acceleration & $\mathrm{m} / \mathrm{s}^{2}$ & $n$ \\
Length & $\mathrm{m}$ & $1 / n$ \\
Volume & $\mathrm{m}^{2}$ & $1 / n^{3}$ \\
Gravity & $\mathrm{kg} \cdot \mathrm{m} / \mathrm{s}^{2}$ & $1 / n^{2}$ \\
Density & $\mathrm{kg} / \mathrm{m}^{3}$ & 1 \\
Unit weight & $\mathrm{N} / \mathrm{m}^{3}$ & $n$ \\
Strain & $\mathrm{N} / \mathrm{m}^{2}$ & 1 \\
Stress & - & 1 \\
Bending moment & $\mathrm{N} / \mathrm{m}$ & $1 / n^{3}$ \\
Force & $\mathrm{N}$ & $1 / n^{2}$ \\
Time & $\mathrm{s}$ & $1 / n^{2}$ \\
\hline
\end{tabular}

soil boxes and strain gauges were examined to verify that they are in proper working condition.

3.2. Scaling Law. The tunnel tests were conducted either under $1 \mathrm{~g}$ or $n \mathrm{~g}$ in a centrifuge. The aim of the centrifugal tests was to increase the stress level by increasing the magnitude of the gravity field for better modeling effects $[19,30$, 32]; however, the scaling law should meet the requirements of consistence between the prototype and the model. In this test, the size of model box was $700 \mathrm{~mm}$ (length) $\times 360 \mathrm{~mm}$ (width) $\times 500 \mathrm{~mm}$ (height). The ratio of similitude $n$ was taken as 60 , based on those in the previous research work $[16,28]$. The scaling law of each project for this test is shown in Table 2. On the other hand, the equivalent principle proposed by Taylor $[29,30]$, under the condition of lateral
TABLe 3: Test conditions.

\begin{tabular}{lcc}
\hline Collapsible condition & $\begin{array}{c}\text { Foundation } \\
\text { collapsible depth }\end{array}$ & Test project \\
\hline Half-range soaking & Soaking depth: $5 \mathrm{~cm}$ & $\begin{array}{c}\text { Soil pressure } \\
\text { (E1 E8) } \\
\text { Fending moment } \\
(\mathrm{S} 1 \sim \mathrm{S} 8)\end{array}$ \\
Sull-range soaking & Soaking depth: $10 \mathrm{~cm}$ & $\begin{array}{c}\text { Ground surface } \\
\text { settlement }\end{array}$ \\
\hline
\end{tabular}

bending, was applied for computation of bending stiffness. The relationship between the bending moments of the prototype and the model is given by $E_{\mathrm{m}} I_{\mathrm{m}}=n^{-3} E_{\mathrm{p}} I_{\mathrm{p}}$, where $E_{\mathrm{m}}$ and $E_{\mathrm{p}}$ are the elastic modulus of the model and the prototype and $I_{\mathrm{m}}$ and $I_{\mathrm{p}}$ are the moments of inertia of the model and the prototype, respectively. The moment of inertia was calculated according to the relationship $I=t^{3} / 12$, where $t$ is the thickness. Then, the tunnel model was equivalent to a concrete tunnel with a thickness of $350 \mathrm{~mm}$ and an elastic modulus of $30 \mathrm{GPa}$.

There are some limitations in the centrifugal technique, such as the variation of the magnitude and the direction of gravity throughout the model $[13,34,36]$, the influence of the soil's gravity on the gravity field, and impossibility of scaling the soil grains $[16,33]$. The scaling laws were not totally applied for the interface properties between the tunnel and the model soil. These issues were checked in the model firstly, and their effects were found to be below a certain threshold, but the grain size could not be reduced by the scaling factor [33]. In this study, the prototype material was used, with respect to the study of Chambon and Corté [46]. The ratio of the tunnel diameter to mean grain diameter $d_{50}$ in the test is 2857 which is greater than the threshold proposed by Soranzo et al. [33], and therefore, the grain-size effect could be neglected.

3.3. Test Conditions and Setup. In this test, the influence of both half-range soaking and full-range soaking of foundation with different soaking depths on metro tunnel structures in collapsible loess would be studied. The soil pressure and the ground settlement were measured, respectively, and the bending moment was calculated from the strain value. The buried depth of the tunnel model, the distance from the ground to the inverted arch, and the foundation depth was $15 \mathrm{~cm}, 25 \mathrm{~cm}$, and $15 \mathrm{~cm}$, respectively. Three collapsible conditions (the depths of collapsible foundation soaking were chosen as $5 \mathrm{~cm}, 10 \mathrm{~cm}$, and $15 \mathrm{~cm}$ ) were considered. The test conditions are listed in Table 3. Take the section at the middle of the tunnel model as the representative section, where eight soil pressure points (E1-E8) and eight bending moment points (S1-S8) were placed around the tunnel. The soil pressure was measured by a miniature earth pressure cell, and the bending moment was obtained by the formulation $M=E\left(\varepsilon_{i}-\varepsilon_{e}\right) b h^{2} / 12$, where $b$ is the unit length, $h$ is the lining thickness, $E$ is the lining elastic modulus, $\varepsilon_{e}$ is the outer strain of lining, and $\varepsilon_{i}$ is the inner strain of lining which can be measured by the four strain gauges in the full 

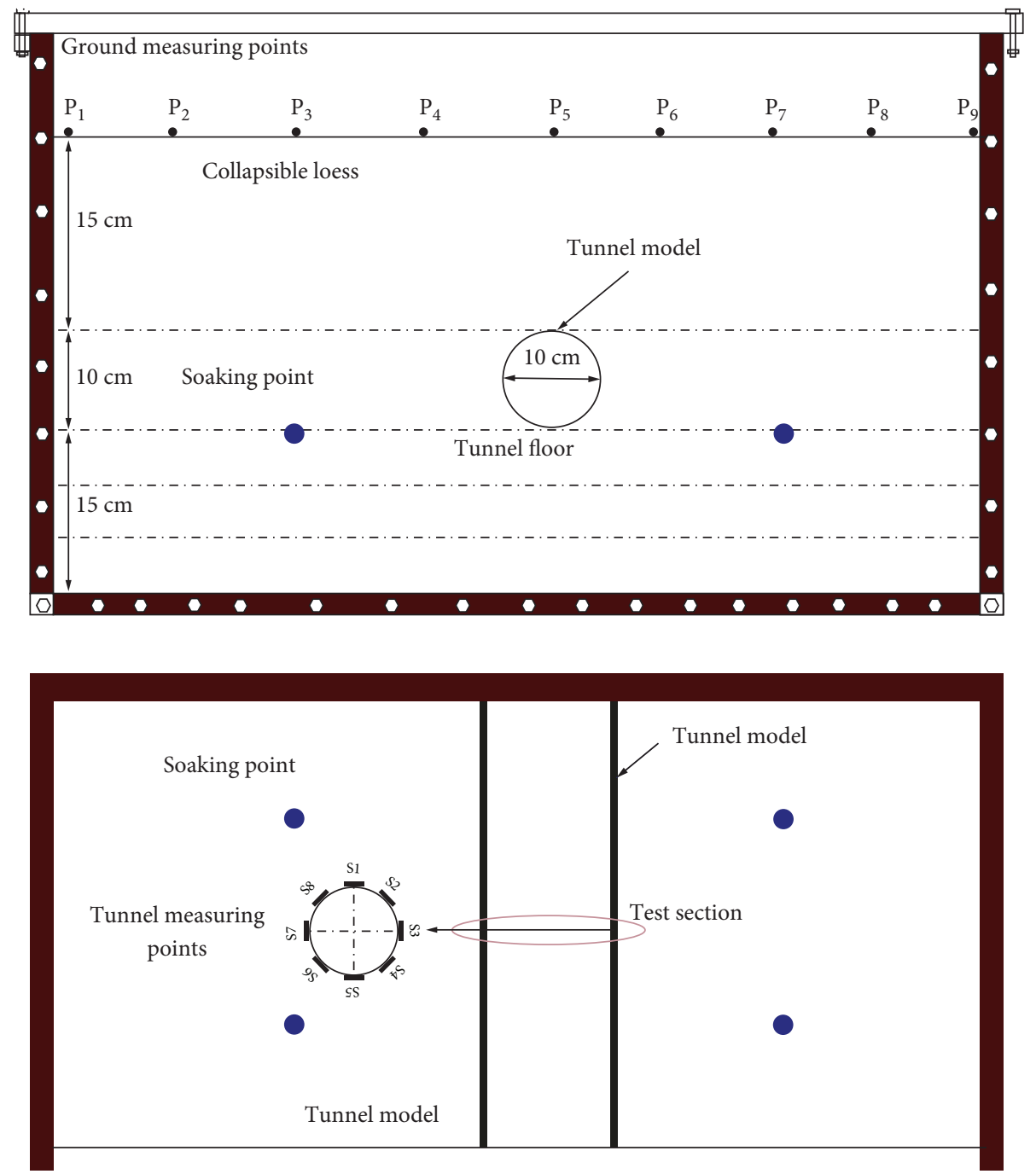

Figure 7: Design of test section and points.

bridge converter. Furthermore, the ground settlement was obtained by a laser displacement sensor. The test section and the test points are shown in Figure 7. A suitable length was chosen for the soaking probe, and the water volume in the cistern was calculated with respect to the foundation soaking depth by $110 \%$. The acceleration of the centrifugal was then increased to $60 \mathrm{~g}$, and when the centrifugal operation was stable, the foundation began to be immersed by controlling the solenoid valve. Till the water in the cistern was up and foundation soaking was homogeneous, the centrifugal operation was stopped. A similar procedure was adopted in the rest of the tests with the exception of the soaking probe and the water volume in the cistern. Throughout each test condition, the soil pressure, the induced bending moment, and the ground surface settlement were recorded.

\section{Results and Discussion}

4.1. Soil Pressure. The soil pressure of half-range soaking in different foundation soaking depths with operating time is shown in Figure 8; as can be seen from Figure 8, there are three segments which are initial segment, increasing segment, and the stable segment in the curve; the change of soil pressure in the initial segment is small, because the water soaking effect was not so obvious in the beginning. Along with the operating time, the water soaking depth in the foundation was bigger and the water soaking effect was more uniform, and the soil pressure came into the increasing segment, in which the soil pressure has a drastic change with some characteristic stages. In the characteristic stage, the soil pressure may change bigger or smaller for the cause of an uneven water soaking effect in the foundation. In the last, the soil pressure curve reached the stable segment with the loess foundation reaching the saturated collapsible state. In addition, the soil pressure change in different measuring points around the tunnel was different obviously, the soil pressure in $135^{\circ}$ and $180^{\circ}$ was decreasing, and the other points were increasing for the cause of foundation soaking. The soil pressures of different soaking depths in the final state for halfrange soaking are given in Figure 9. As can be seen from Figure 9, the soil pressure on the left part increased, but that on the right part decreased which is because the strength of 


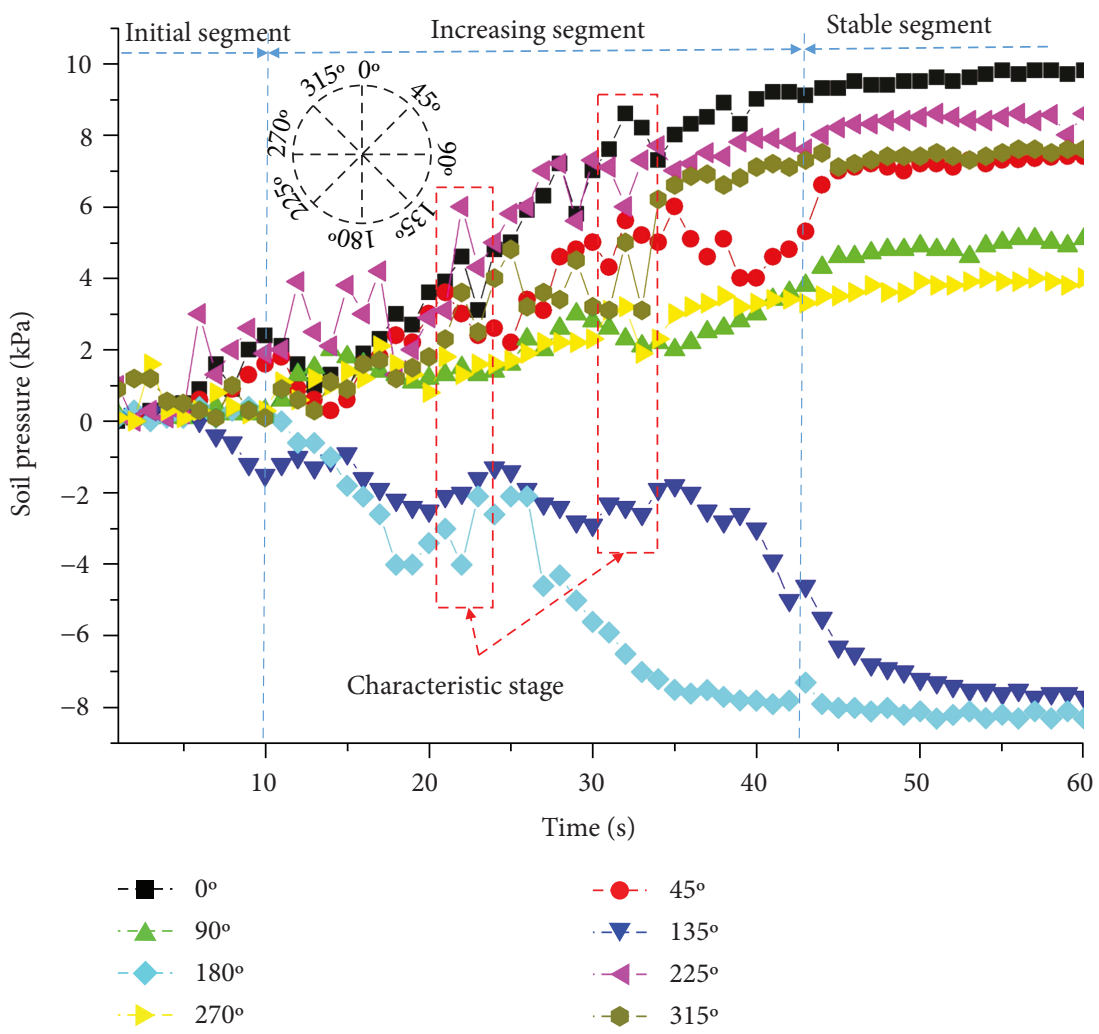

(a) Soaking depth: $5 \mathrm{~cm}$

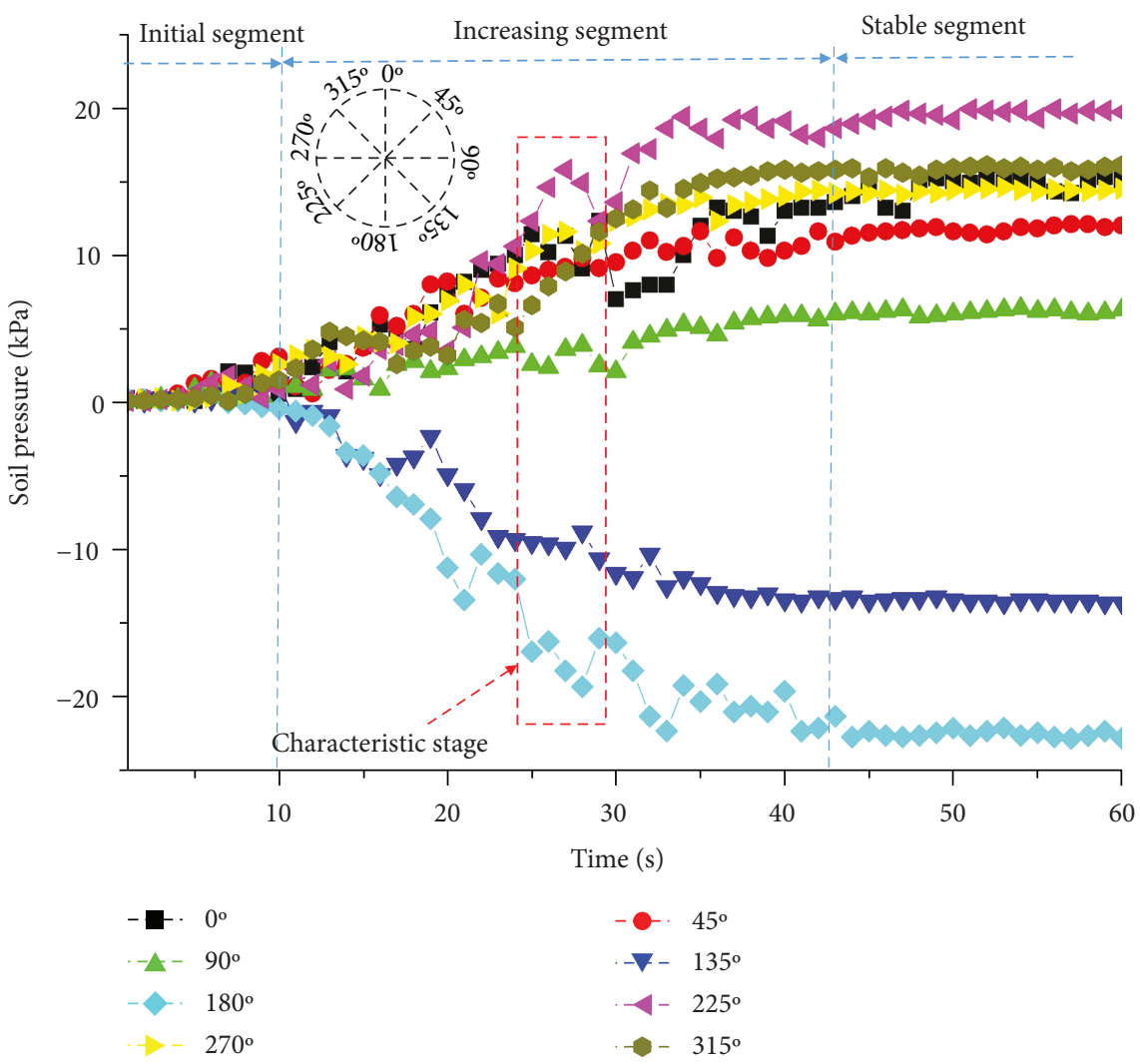

(b) Soaking depth: $10 \mathrm{~cm}$

FIgURE 8: Continued. 


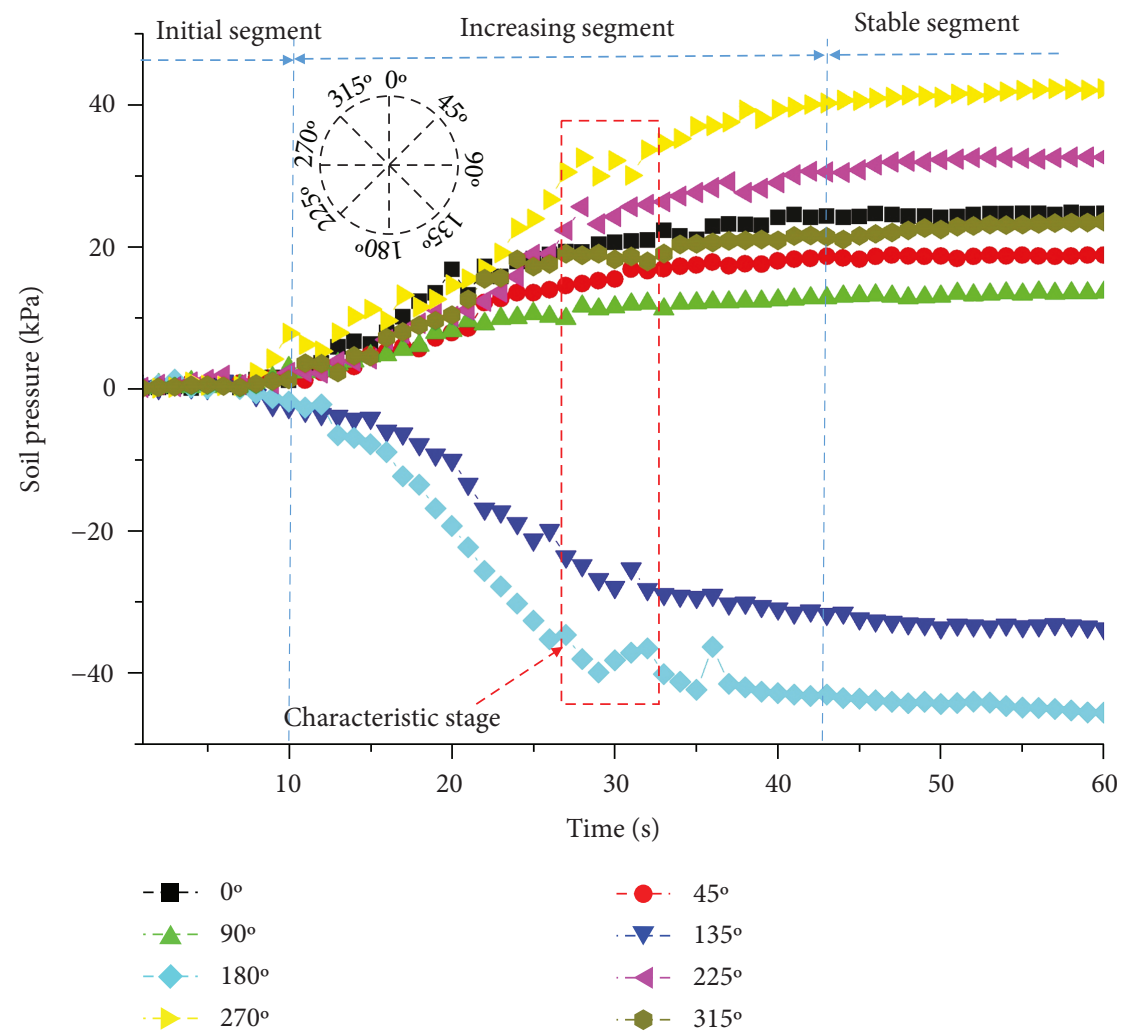

(c) Soaking depth: $15 \mathrm{~cm}$

FIGURE 8: Soil pressure of half-range soaking with operating time.

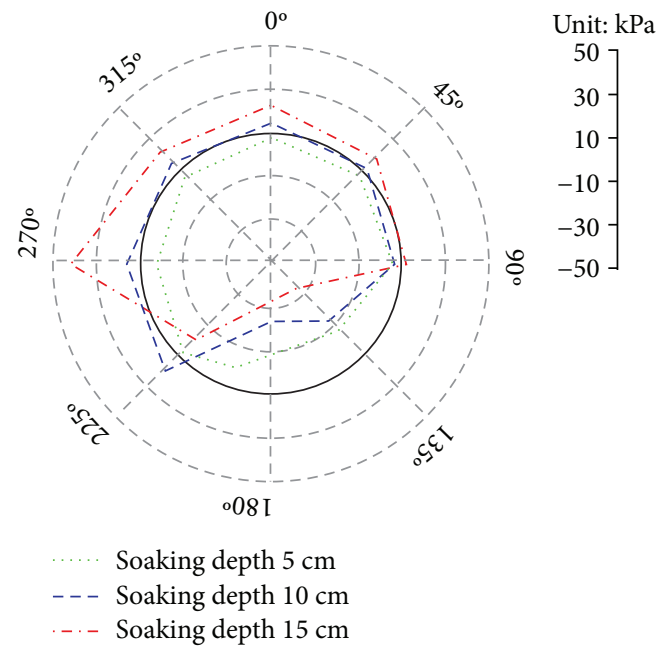

FIGURE 9: Soil pressure of half-range soaking in final state.

the soil on the right part of the foundation had been reduced owing to the soaking effect, whereas it kept unchanged for the left part. Therefore, a heavier load was carried out by the left part of the soil. The load on the tunnel vault also increased, but its amplification was smaller than that of the inverted arch. The influence of the soaking on the mechanical characteristics of the tunnel becomes more significant with the collapsible depth of the foundation, when the collapsible depth of the foundation soaking was $5 \mathrm{~cm}$, the soil pressure at $225^{\circ}$ was increased by $7.3 \mathrm{kPa}$, and when it was $15 \mathrm{~cm}$, the corresponding value was $31 \mathrm{kPa}$.

The soil pressure of full-range soaking in different foundation soaking depths with operating time is shown in Figure 10. From Figure 10, we can see that there are also three segments which are initial segment, increasing segment, and stable segment in the curve, but the initial segment was shortly subjected to the bigger water soaking rate, and along with the operating time, the soil pressure came into the increasing stage earlier. The soil pressure has a more drastic change in the characteristic stage for the cause of a more obvious water soaking effect in the foundation. In the last, the soil pressure curve reached the stable segment too with the loess foundation reaching the saturated state. The soil pressure change in different measuring points around the tunnel was different obviously, the soil pressure in $135^{\circ}$, $180^{\circ}$, and $225^{\circ}$ was decreasing, and the other points were increasing for the cause of foundation soaking. The soil pressures of different soaking depths in the final state for halfrange soaking are given in Figure 11. It can be seen from Figure 11 that the strength and bearing capacity of the foundation decreased under the condition of full-range soaking which led to an increase in the soil pressure at $0^{\circ}, 45^{\circ}, 90^{\circ}$, $270^{\circ}$, and $325^{\circ}$ This is because the full-range foundation bearing capacity decreased owing to its soaking, and the loess that is located above was bearing more loads. When the soaking depth of foundation was $5 \mathrm{~cm}$, the soil pressure at $180^{\circ}$ was only decreased by $6 \mathrm{kPa}$, and it was $15 \mathrm{~cm}$; the decrease was $39.1 \mathrm{kPa}$. It is also seen that the strength reduction of 


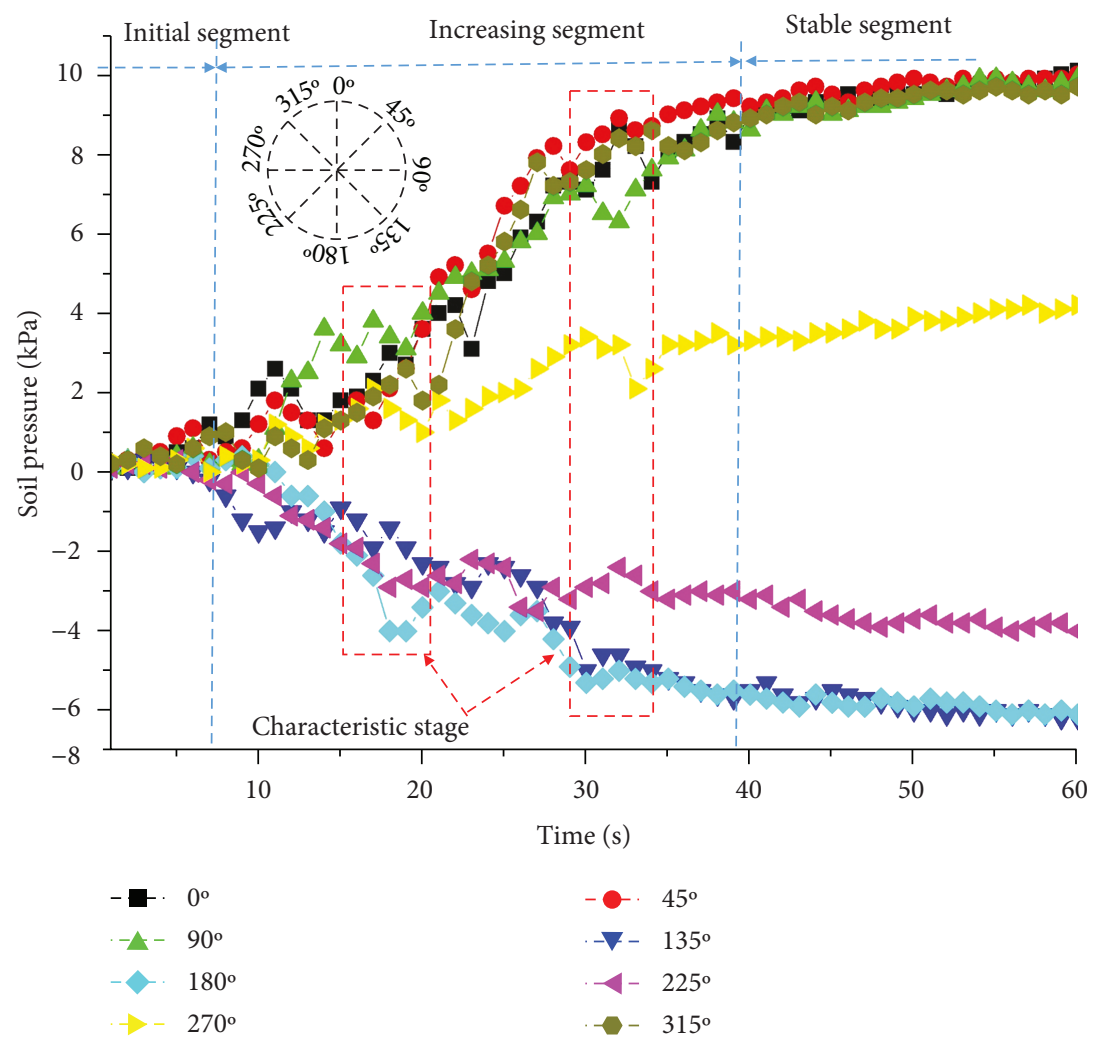

(a) Soaking depth: $5 \mathrm{~cm}$

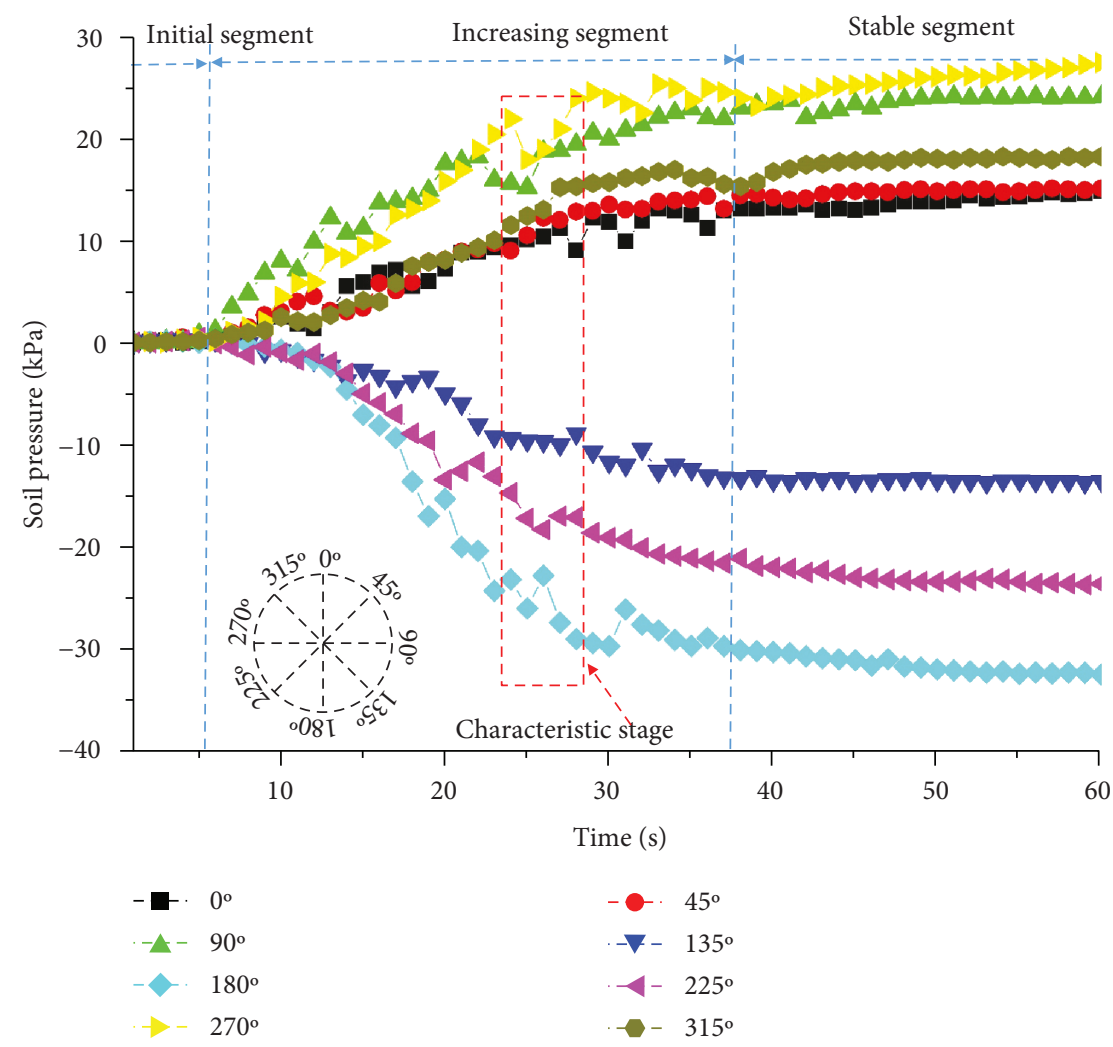

(b) Soaking depth: $10 \mathrm{~cm}$

Figure 10: Continued. 


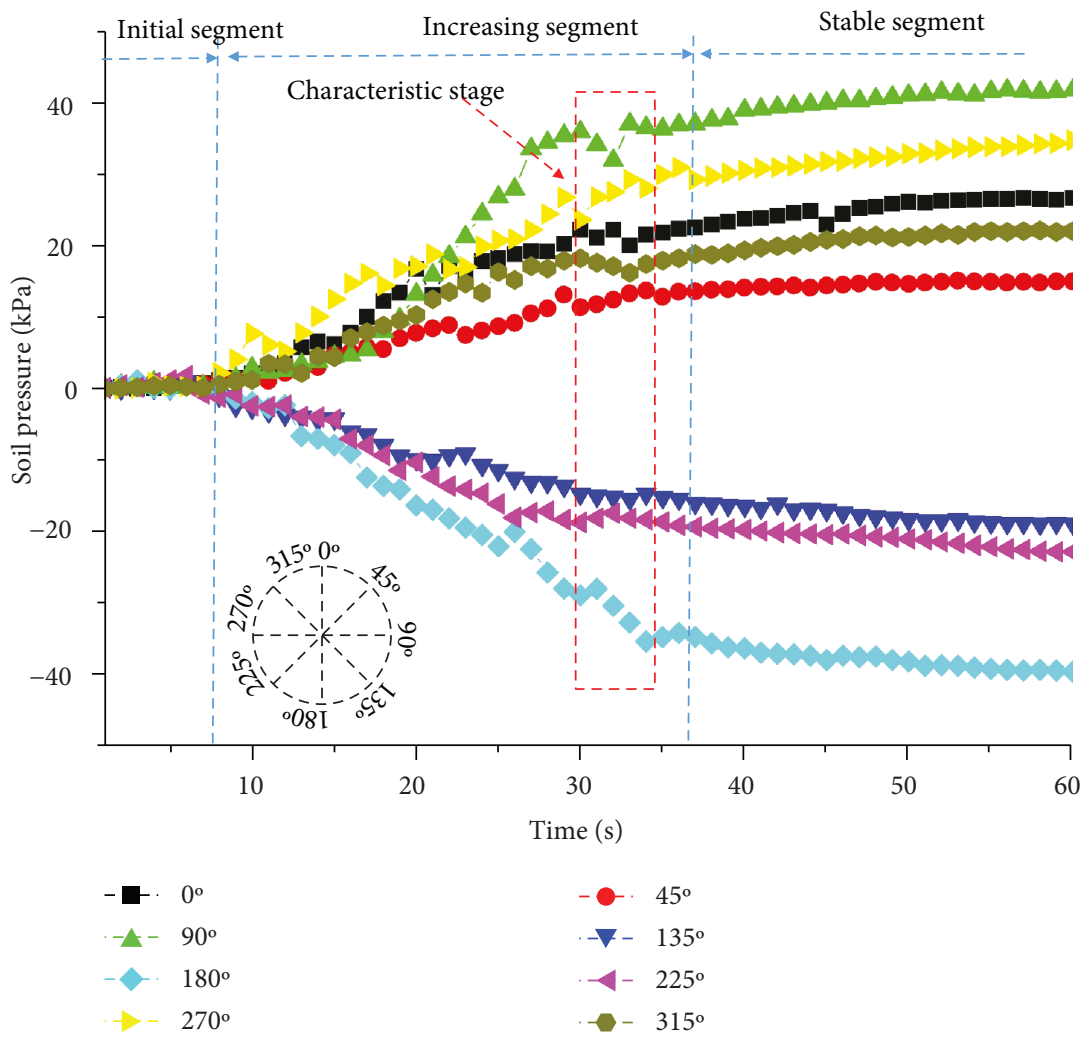

(c) Soaking depth: $15 \mathrm{~cm}$

FIGURE 10: Soil pressure of full-range soaking with operating time.

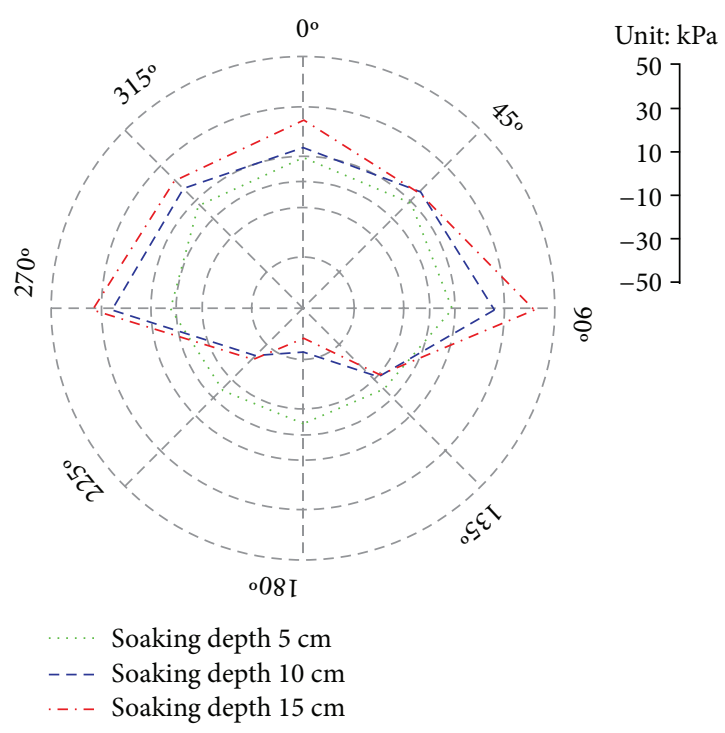

FIGURE 11: Soil pressure of full-range soaking in final state.

the foundation led to a redistribution of the loads in the tunnel, which may lead to lining cracks. As in the similar rule above, the deeper the collapsible depth of foundation soaking, the more significant is the influence. What is more, the effect is more significant for half-range soaking than that for full-range soaking. It could be inferred that uneven stress caused by half-range soaking in the foundation was the main reason for the tunnel cracking problem, such as the lining cracks, the differential settlement, and stress redistribution. When the collapsible foundation depth was only $5 \mathrm{~cm}$, the influence of foundation soaking on the tunnel becomes negligible and therefore dealing the collapsible foundation with a noncollapsible depth is a helpful way for the improvement of the mechanical characteristics of the tunnel. However, the determination of the optimum treatment depth of the collapsible foundation needs to be studied further.

4.2. Bending Moment. The bending moment of half-range soaking in different foundation soaking depths with operating time is given in Figure 12, where it is shown that there are three segments which are initial segment, increasing segment, and stable segment; when the foundation soaking depth was $5 \mathrm{~cm}$, the bending moment at $90^{\circ}$ and $270^{\circ}$ was decreased, the other points were increased, and the points at $0^{\circ}$ and $45^{\circ}$ had the most obvious increased values. The values in the initial segment and stable segment were steady; however, the value in the initial segment was changed acutely, particularly in the characteristic stage. The value change which was bigger or smaller subjected to the soaking depth was uneven. When the soaking depth was $10 \mathrm{~cm}$, the initial segment became shorter, and the bending moment in the increasing segment had a more acute change. The bending moment at $0^{\circ}$ decreased firstly and then increased with operating time; in the characteristic stage, there was an obvious inflexion. When the soaking depth was $15 \mathrm{~cm}$, the initial segment was becoming shorter further, and the inflexion of 


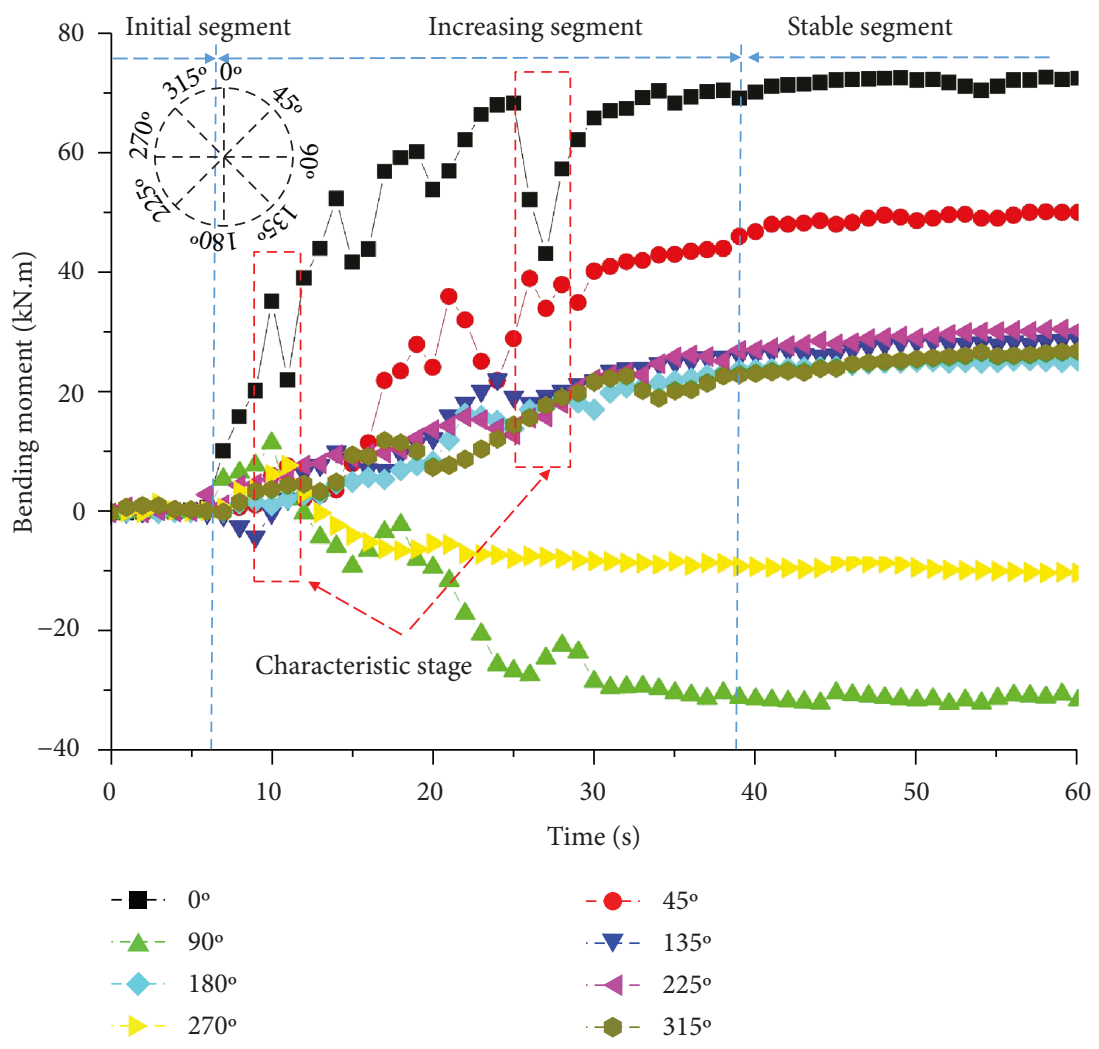

(a) Soaking depth: $5 \mathrm{~cm}$

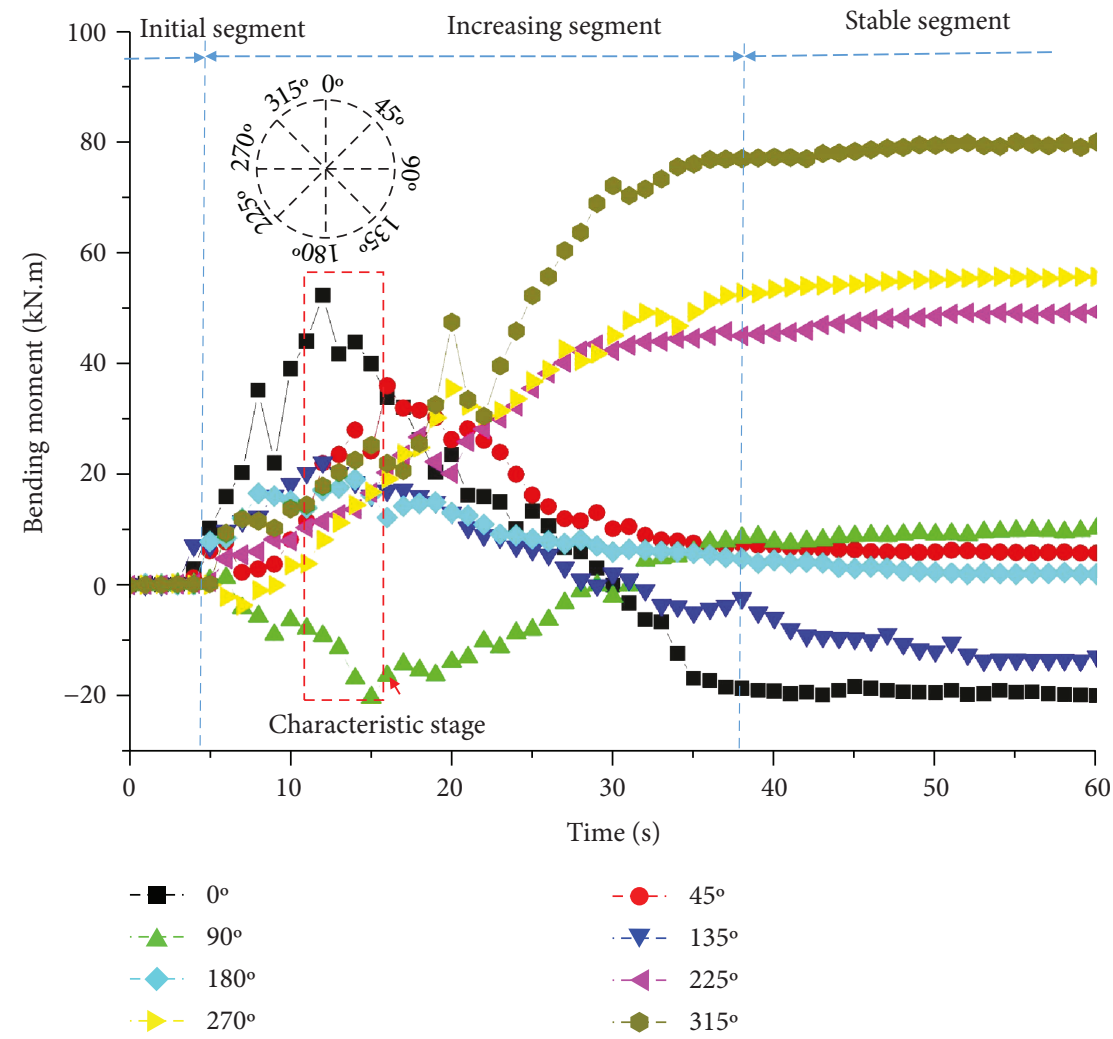

(b) Soaking depth: $10 \mathrm{~cm}$

Figure 12: Continued. 


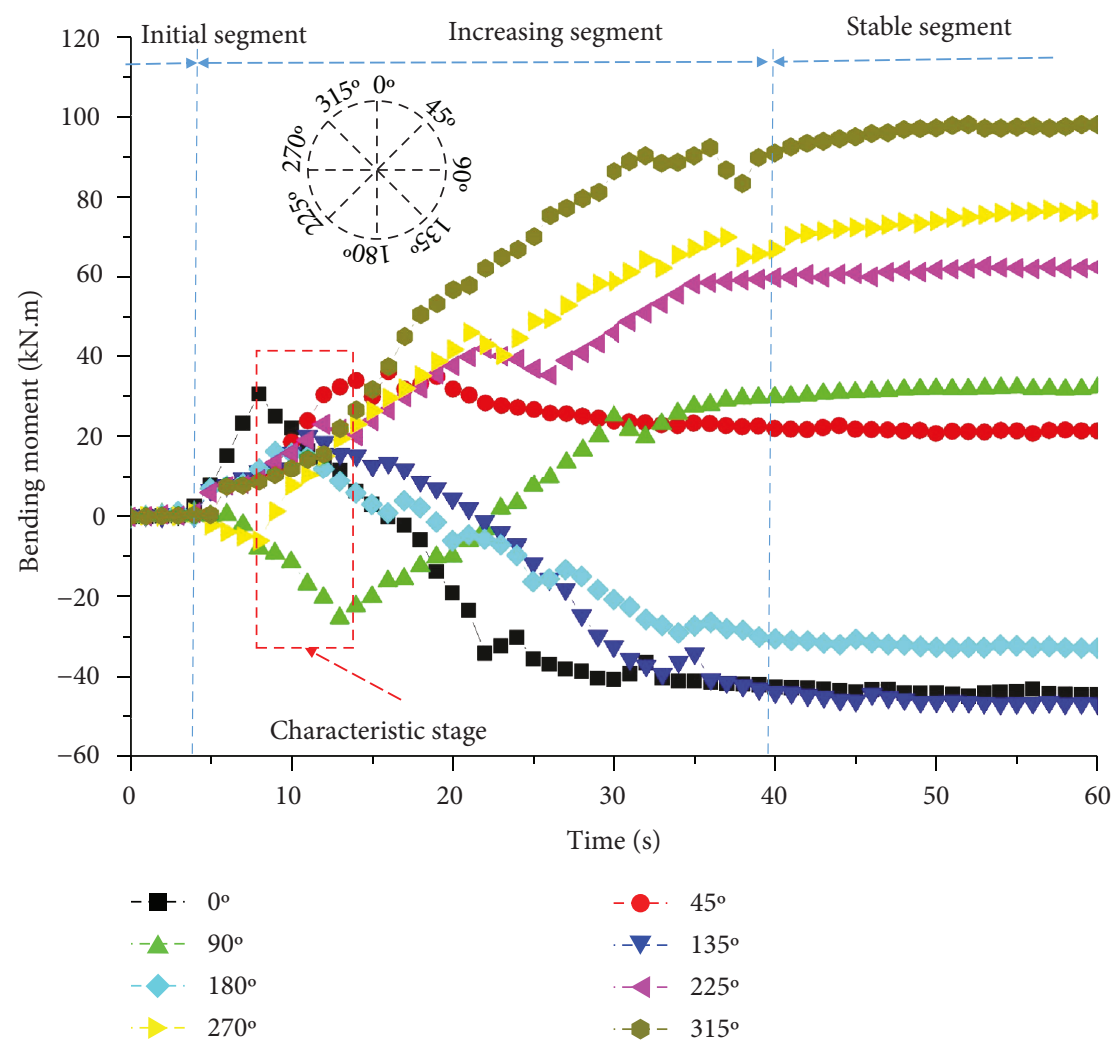

(c) Soaking depth: $15 \mathrm{~cm}$

FIGURE 12: Bending moment of half-range soaking with operating time.

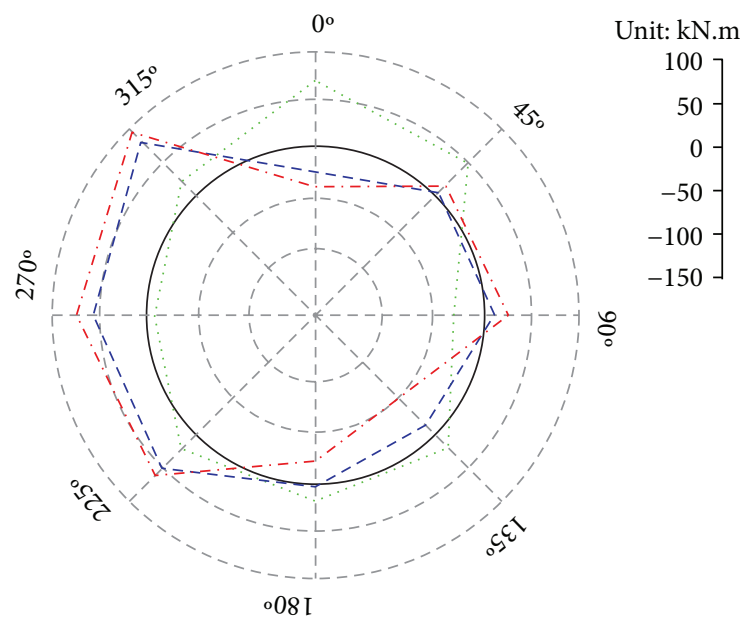

Soaking depth $5 \mathrm{~cm}$

-- - Soaking depth $10 \mathrm{~cm}$

-. - Soaking depth $15 \mathrm{~cm}$

Figure 13: Bending moment of half-range soaking in final state.

the curve came earlier; the value at $90^{\circ}$ decreased at first and then increased in the increasing segment. In the last, all the values of the measuring points came into the stable segment with the loess foundation reaching the saturated state. The bending moment of half-range soaking with different soaking depths in the final state is given in Figure 13, where it is shown that, when the collapsible foundation soaking depth was $15 \mathrm{~cm}$, the bending moment at the left part of the foundation increased significantly, and the maximum value reached $98 \mathrm{kN} . \mathrm{m} / \mathrm{m}$. Moreover, the magnitude of the variations of the bending moment decreases with the foundation collapsible depth. When the soaking depth was $5 \mathrm{~cm}$, the change in bending moment was not significant.

The bending moment of full-range soaking in different foundation soaking depths with operating time is given in Figure 14, from which we can see that the bending moment grows stably relatively compared to the results of half-range soaking, and the initial segment was becoming shorter with the increase in soaking depth. When the soaking depth was $5 \mathrm{~cm}$, the bending moment at $0^{\circ}$ increased obviously; however, it decreased at $135^{\circ}$ and $270^{\circ}$. When the soaking depth was $10 \mathrm{~cm}$, the increasing segment came earlier with an obvious inflexion in the curve, and the values at $135^{\circ}$ and $270^{\circ}$ decreased at first and then increased with the soaking depth; the values at $0^{\circ}$ and $180^{\circ}$ have an opposite changing trend. When the soaking depth was $15 \mathrm{~cm}$, the initial segment was the shortest; it has a similar changing trend with the results of the soaking depth in the increasing segment. The bending moment of full-range soaking with different soaking depths in the final state is given in Figure 15, and it is shown that when the soaking depth was $5 \mathrm{~cm}$, the bending moment at $0^{\circ}$ and $180^{\circ}$ was bigger than the value in other points. However, when the soaking depth was $10 \mathrm{~cm}$, the bending moment at $0^{\circ}$ and $180^{\circ}$ was smaller than the value at $90^{\circ}$ and $270^{\circ}$. When the soaking depth was $15 \mathrm{~cm}$, the bending moment at $0^{\circ}$ and $180^{\circ}$ was smaller and the value at $90^{\circ}$ and $270^{\circ}$ was 

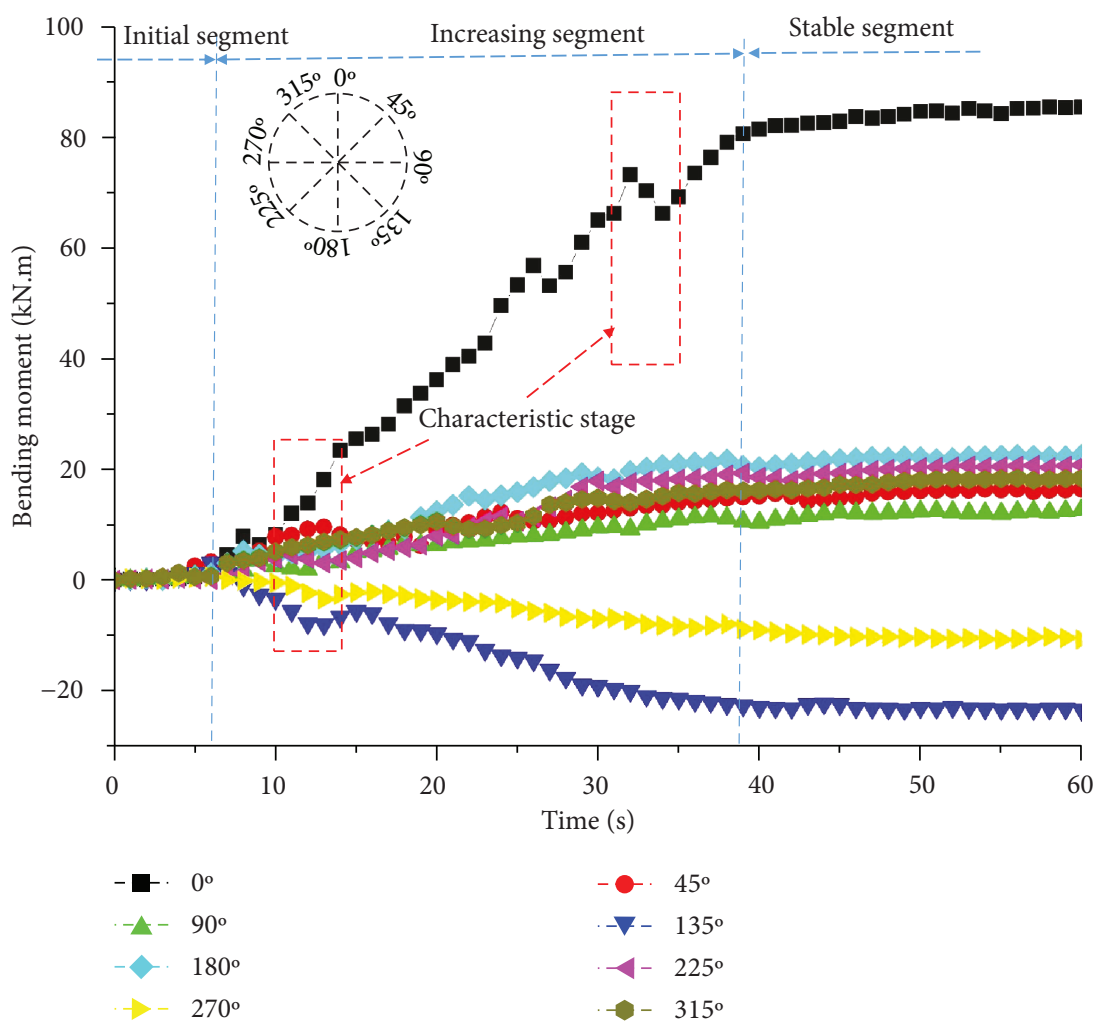

(a) Soaking depth: $5 \mathrm{~cm}$

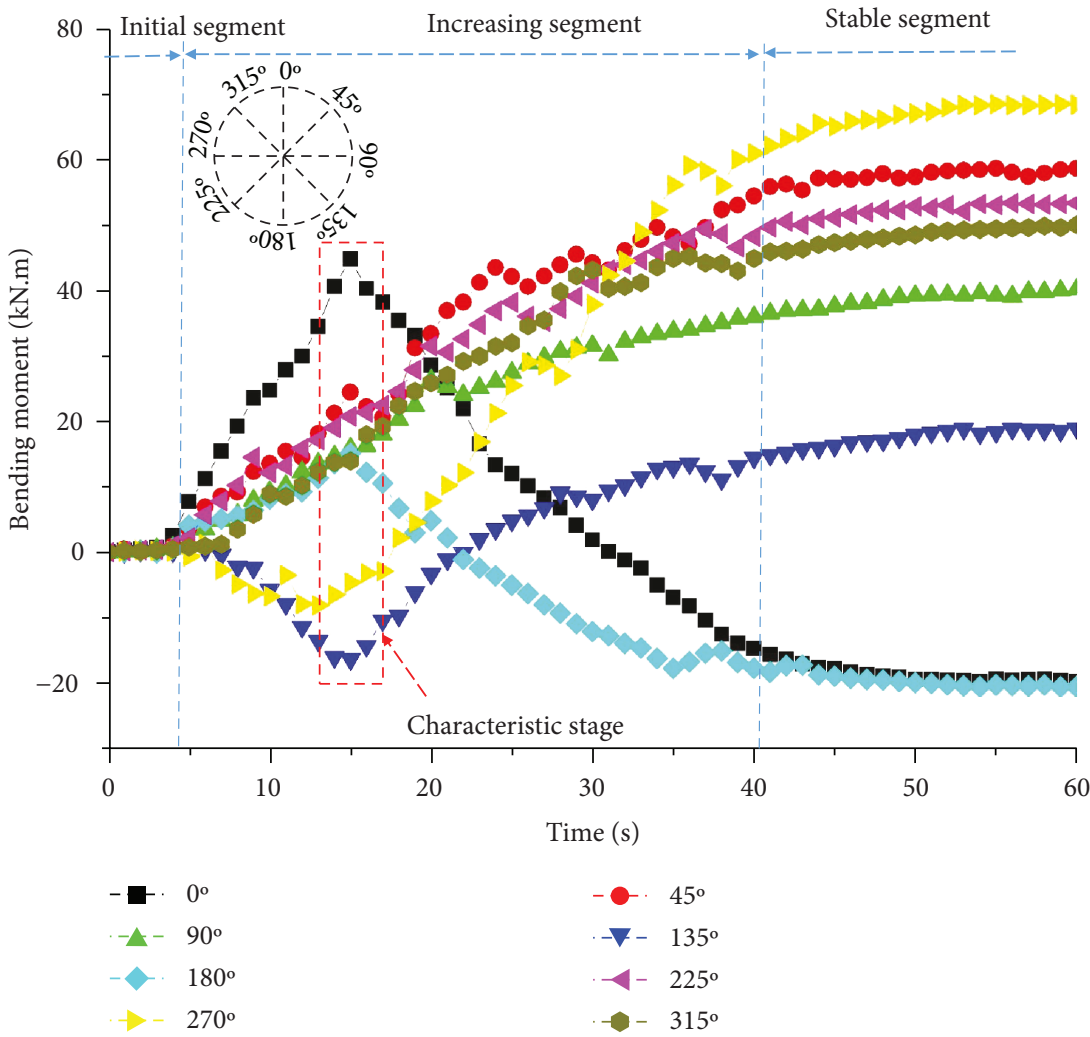

(b) Soaking depth: $10 \mathrm{~cm}$

Figure 14: Continued. 


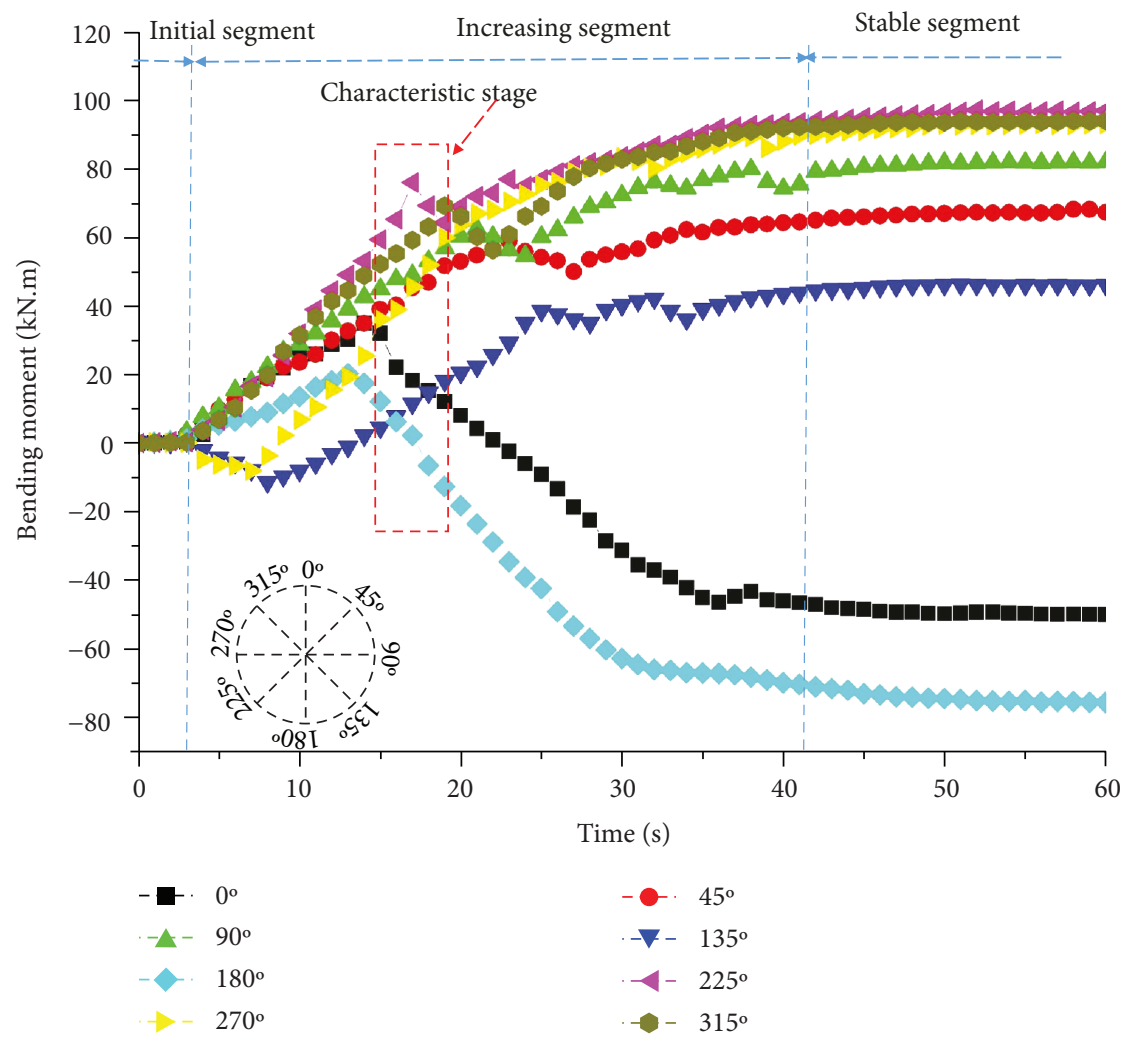

(c) Soaking depth: $15 \mathrm{~cm}$

Figure 14: Bending moment of full-range soaking with operating time.

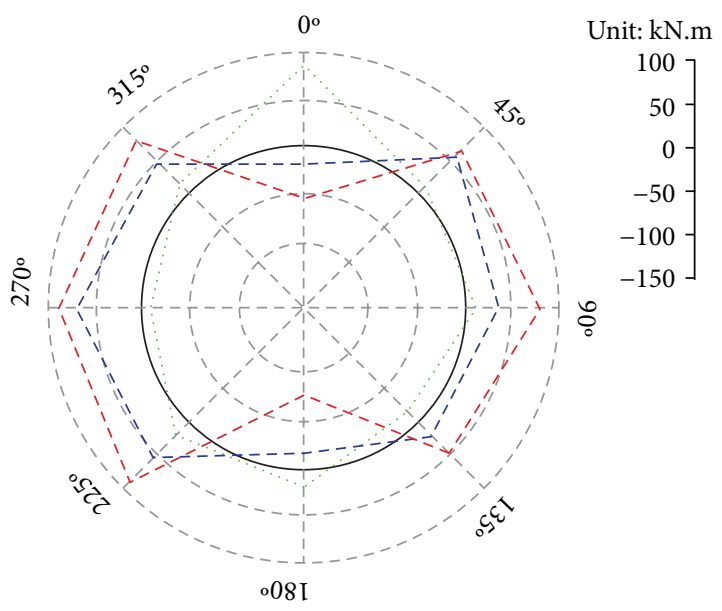

Soaking depth $5 \mathrm{~cm}$

- - Soaking depth $10 \mathrm{~cm}$

-.- Soaking depth $15 \mathrm{~cm}$

Figure 15: Bending moment of full-range soaking in final state.

bigger; this is because of the foundation soaking leading to the redistribution of the bending moment in the tunnel.

From the comparison of Figures 13 and 15, it can also be seen that the tunnel structure is less affected by full-range soaking compared with that by half-range soaking. Nonuniform settlement will be caused owing to the moisture migration in the soil under the condition of full-range soaking. As a result, half-range soaking could be more harmful to the metro tunnel structure particularly when the collapsible foundation depth is large. The differential foundation settlement caused by half-range soaking may be one of the main reasons for the tunnel cracks. The harmful effect of foundation soaking increases with the depth of the collapsible loess foundation which, therefore, should be treated at a noncollapsible depth reasonably in practice.

4.3. Ground Surface Settlement. The ground surface settlement for half-range soaking and full-range soaking with different soaking depths was given in Figures 16 and 17, respectively, where it can be seen that the settlement of fullrange soaking was higher than that of half-range soaking. There was only one peak in the settlement curve of halfrange soaking, but there were two peaks in the curve of full-range soaking; the value at the soaking point is the biggest. The deeper the soaking depth, the bigger the settlement induced by soaking. When the collapsible depth was $15 \mathrm{~cm}$, the maximum settlement for full-range soaking was $7.1 \mathrm{~mm}$, which was only $5.2 \mathrm{~mm}$ for half-range soaking. However, the changes of bending moment were larger under the condition of half-range soaking and it could be deduced that the nonuniform settlement was the main reason for the tunnel breakage. Furthermore, when the collapsible depth was $5 \mathrm{~cm}$, the settlements for both half-range soaking and full-range soaking were small and the changes in bending moment were not significant. It could be concluded that the deeper the treatment depth of the foundation, the stronger 


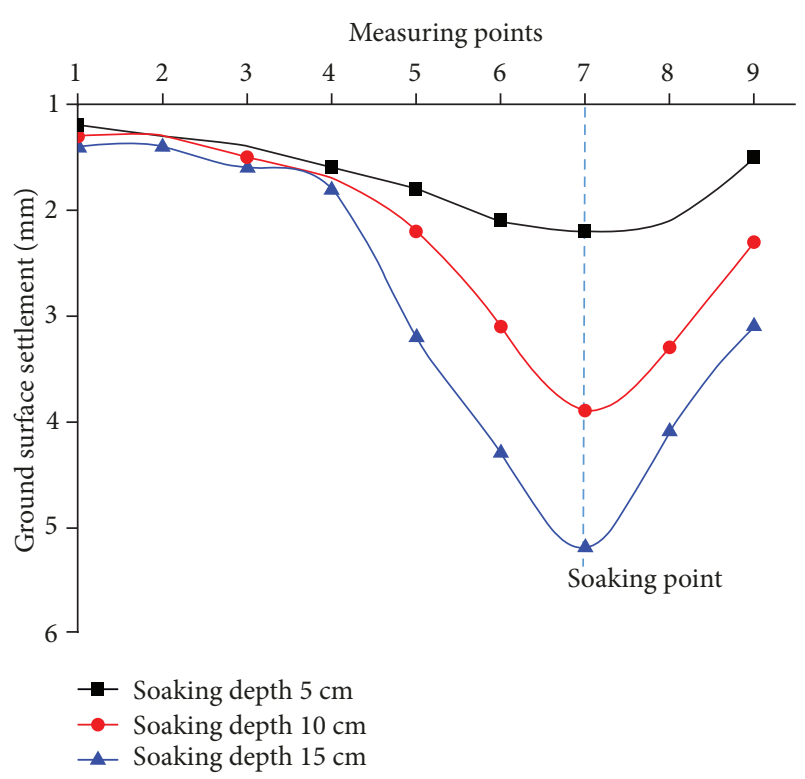

FIGURE 16: Ground surface settlement for half-range soaking.

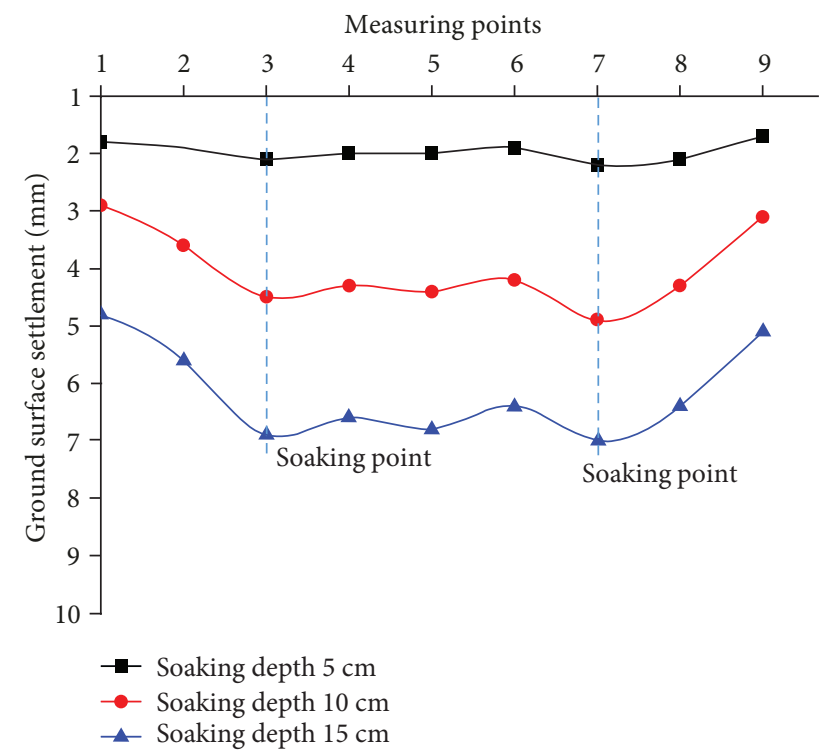

FIGURE 17: Ground surface settlement for full-range soaking.

the resistance to deformation. The tunnel would be less affected by soaking in the loess layer. Hence, it is necessary to choose an appropriate treatment depth of the collapsible foundation to reduce the diseases of the metro tunnel structure, and another effective way is to alleviate the uneven foundation soaking.

\section{Conclusions}

In this paper, a WSS was improved based on CTE, which could simulate various foundation-collapsible conditions caused by water soaking for a metro tunnel, and the capability of the WSS was verified by a few centrifugal soaking tests. The WSS was applied for the simulation of metro tunnel foundation soaking. A series of tests for full-range soaking and half-range soaking with different soaking depths of the metro tunnel were conducted. The influence of foundation soaking on the tunnel structure was analyzed in detail. The key findings are as follows:

(1) Half-range foundation soaking and full-range foundation soaking tests were conducted by the remodeled loess. The results show that the water soaking capability of the WSS could satisfy the requirements of testing

(2) The metro tunnel was impacted obviously subjected to the foundation soaking in the collapsible loess. Both full-range and half-range foundation soaking would result in a redistribution of the stress in the tunnel. Half-range soaking was found to be more harmful to the mechanical properties of the tunnel than the full-range foundation soaking was

(3) The collapsible deformation was uneven induced by half-range foundation soaking, but was even induced by full-range foundation soaking. The differential deformation caused by half-range foundation soaking was one of the main reasons for the tunnel cracks. The deeper the foundation soaking depth was, the more significant the harmful impacts on tunnel, and it is advised that the collapsible foundation of the metro tunnel should be treated with a reasonable noncollapsible depth

(4) The ground settlement induced by full-range foundation soaking was more obvious than half-range foundation soaking was, which increased with the foundation soaking depth. The half-range foundation soaking leads to local settlement, which may be bad for the ground surface architecture. The chosen appropriate foundation treatment depth was also helpful to control the ground settlement

\section{Data Availability}

The data used to support the findings of this study are available from the corresponding author upon request.

\section{Conflicts of Interest}

The authors declare that there is no conflict of interests regarding the publication of this paper.

\section{Acknowledgments}

The authors would like to acknowledge the National Natural Science Foundation of China (Grant Nos. 51378004 and 51578447), China Postdoctoral Science Foundation Project (2018M643809XB), and Xi'an University of Architecture and Technology Talent Foundation (Grant No. RC1802), which collectively funded this project. 


\section{References}

[1] Y. Li, S. Xu, H. Liu, E. Ma, and L. Wang, "Displacement and stress characteristics of tunnel foundation in collapsible loess ground reinforced by jet grouting columns," Advances in Civil Engineering, vol. 2018, Article ID 2352174, 16 pages, 2018.

[2] J. L. Qiu, Y. W. Qin, J. X. Lai et al., "Structural response of the metro tunnel under local dynamic water environment in loess strata," Geofluids, vol. 2019, Article ID 8541959, 16 pages, 2019.

[3] X. Weng, Y. Zhao, Y. Lou, and J. Zhan, “Application of fiber Bragg grating strain sensors to a centrifugal model of a jacked pile in collapsible loess," Geotechnical Testing Journal, vol. 39, no. 3, pp. 362-370, 2016.

[4] J. Qiu, X. Wang, J. Lai, Q. Zhang, and J. Wang, "Response characteristics and preventions for seismic subsidence of loess in Northwest China," Natural Hazards, vol. 92, no. 3, pp. 1909-1935, 2018.

[5] J. Lai, S. He, J. Qiu et al., "Characteristics of seismic disasters and aseismic measures of tunnels in Wenchuan earthquake," Environmental Earth Sciences, vol. 76, no. 2, p. 94, 2017.

[6] J. Lai, K. Wang, J. Qiu, F. Niu, J. Wang, and J. Chen, "Vibration response characteristics of the cross tunnel structure," Shock and Vibration, vol. 2016, Article ID 9524206, 16 pages, 2016.

[7] W.-C. Cheng, J. C. Ni, A. Arulrajah, and H.-W. Huang, "A simple approach for characterising tunnel bore conditions based upon pipe-jacking data," Tunnelling and Underground Space Technology, vol. 71, pp. 494-504, 2018.

[8] Z. Wang, Z. Hu, J. Lai, H. Wang, K. Wang, and W. Zan, "Settlement characteristics of jacked box tunneling underneath a highway embankment," Journal of Performance of Constructed Facilities, vol. 33, no. 2, article 04019005, 2019.

[9] Y. Zhang, Z. Song, X. Weng, and Y. Xie, "A new soil-water characteristic curve model for unsaturated loess based on wetting-induced pore deformation," Geofluids, vol. 2019, Article ID 1672418, 14 pages, 2019.

[10] X. Luo, D. Li, Y. Yang, and S. Zhang, "Spatiotemporal Traffic Flow Prediction with KNN and LSTM," Journal of Advanced Transportation, vol. 2019, Article ID 4145353, 10 pages, 2019.

[11] J. Qiu, X. Wang, S. He, H. Liu, J. Lai, and L. Wang, “The catastrophic landside in Maoxian County, Sichuan, SW China, on June 24, 2017," Natural Hazards, vol. 89, no. 3, pp. 1485-1493, 2017.

[12] D. Zhang, Q. Fang, P. Li, and L. N. Y. Wong, "Structural responses of secondary lining of high-speed railway tunnel excavated in loess ground," Advances in Structural Engineering, vol. 16, no. 8, pp. 1371-1379, 2013.

[13] P. Li, Y. Zhao, and X. Zhou, "Displacement characteristics of high-speed railway tunnel construction in loess ground by using multi-step excavation method," Tunnelling and Underground Space Technology, vol. 51, no. 2, pp. 41-55, 2016.

[14] P. Laut, "Application of centrifugal model tests in connexion with studies of flow patterns of contaminated water in soil structures," Géotechnique, vol. 25, no. 2, pp. 401-406, 1975.

[15] J. Wang, Z. Song, B. Zhao, X. Liu, J. Liu, and J. Lai, “A study on the mechanical behavior and statistical damage constitutive model of sandstone," Arabian Journal for Science and Engineering, vol. 43, no. 10, pp. 5179-5192, 2018.

[16] J. Lai, J. Qiu, H. Fan, Q. Zhang, J. Wang, and J. Chen, "Fiber bragg grating sensors-based in-situ monitoring and safety assessment of loess tunnel," Journal of Sensors, vol. 2016, Article ID 8658290, 10 pages, 2016.

[17] A. N. Schofield, "Cambridge geotechnical centrifuge operations," Géotechnique, vol. 30, no. 3, pp. 227-268, 1980.

[18] W. H. Craig, "Edouard Phillips and the idea of centrifugal modeling," Géotechnique, vol. 39, no. 4, pp. 679-700, 1989.

[19] R. J. Mitchell, "Matrix suction and diffusive transport in centrifuge models," Canadian Geotechnical Journal, vol. 31, no. 3, pp. 357-363, 1994.

[20] M. M. Dewoolkar, H. Y. Ko, and R. Y. S. Pak, "Centrifuge modelling of models of seismic effects on saturated earth structures," Géotechnique, vol. 49, no. 2, pp. 247-266, 1999.

[21] W. A. Charlie, N. A. Dowden, E. J. Villano, G. E. Veyera, and D. O. Doehring, "Blast-induced stress wave propagation and attenuation: centrifuge model versus prototype tests," Geotechnical Testing Journal, vol. 28, no. 2, pp. 12007-12216, 2005.

[22] A. Y. Pasha, L. Hu, J. N. Meegoda, E. Aflaki, and J. Du, "Centrifuge modeling of in situ surfactant enhanced flushing of diesel contaminated soil," Geotechnical Testing Journal, vol. 34, no. 6, pp. 623-633, 2011.

[23] J. Zhou and Y. Tang, "Centrifuge experimental study of thaw settlement characteristics of mucky clay after artificial ground freezing," Engineering Geology, vol. 190, no. 5, pp. 98-108, 2015.

[24] A. De and T. F. Zimmie, "Centrifugal modeling of surface blast effects on underground structures," Geotechnical Testing Journal, vol. 30, no. 5, pp. 427-431, 2007.

[25] G. Zhang, Y. Hu, and J. M. Zhang, "New image analysis-based displacement-measurement system for geotechnical centrifuge modeling tests," Measurement, vol. 42, no. 1, pp. 87-96, 2009.

[26] G. Giardina, M. J. DeJong, and R. J. Mair, "Interaction between surface structures and tunnelling in sand: centrifuge and computational modelling," Tunnelling and Underground Space Technology, vol. 50, no. 9, pp. 465-478, 2015.

[27] S. Divall, R. N. Taylor, and M. Xu, "Centrifuge modelling of tunnelling with forepoling," International Journal of Physical Modelling in Geotechnics, vol. 16, no. 2, pp. 83-95, 2016.

[28] H. B. Liu and N. Soufiane, "Centrifugal modeling of underground tunnel in saturated soil subjected to internal blast loading," Journal of Performance of Constructed Facilities, vol. 30, no. 2, pp. 1-4, 2016.

[29] R. N. Taylor, "Centrifuges in modelling: principles and scale effects," in Geotechnical Centrifuge Technology, pp. 20-34, Blackie Academic and Professional, London, UK, 1995.

[30] Z. J. Zhou, J. T. Lei, S. B. Shi, and T. Liu, "Seismic response of aeolian sand high embankment slopes in shaking table tests," Applied Sciences, vol. 9, no. 4, pp. 1-15, 2019.

[31] N. Depountis, M. C. R. Davies, C. Harris et al., "Centrifuge modelling of capillary rise," Engineering Geology, vol. 60, no. 1-4, pp. 95-106, 2001.

[32] A. Juneja, A. Hegde, F. H. Lee, and C. H. Yeo, "Centrifuge modelling of tunnel face reinforcement using forepoling," Tunnelling and Underground Space Technology, vol. 25, no. 4, pp. 377-381, 2010.

[33] E. Soranzo, R. Tamagnini, and W. Wu, "Face stability of shallow tunnels in partially saturated soil: centrifuge testing and numerical analysis," Géotechnique, vol. 65, no. 6, pp. 454467, 2015.

[34] J. M. Dixon and J. M. Summers, "Recent developments in centrifuge modelling of tectonic processes: equipment, model 
construction techniques and rheology of model materials," Journal of Structural Geology, vol. 7, no. 1, pp. 83-102, 1985.

[35] J. Wang, Q. Huo, Z. Song, and Y. Zhang, "Study on adaptability of primary support arch cover method for large-span embedded tunnels in the upper-soft lower-hard stratum," Advances in Mechanical Engineering, vol. 11, no. 1, pp. 1-15, 2019.

[36] Y. Zhang, B. Bienen, and M. J. Cassidy, "Development of a combined VHM loading apparatus for a geotechnical drum centrifuge," International Journal of Physical Modelling in Geotechnics, vol. 13, no. 1, pp. 13-30, 2013.

[37] P. Shepley and D. M. Bolton, "Water supply to a geotechnical centrifuge," International Journal of Physical Modelling in Geotechnics, vol. 13, no. 3, pp. 99-110, 2013.

[38] C. W. W. Ng, H. Lu, and S. Y. Peng, "Three-dimensional centrifuge modelling of the effects of twin tunnelling on an existing pile," Tunnelling and Underground Space Technology, vol. 35, pp. 189-199, 2013.

[39] J. A. Cox, C. D. O'Loughlin, M. Cassidy, S. Bhattacharya, C. Gaudin, and B. Bienen, "Centrifuge study on the cyclic performance of caissons in sand," International Journal of Physical Modelling in Geotechnics, vol. 14, no. 4, pp. 99-115, 2014.

[40] S. Dashti, Y. M. A. Hashash, K. Gillis, M. Musgrove, and M. Walker, "Development of dynamic centrifuge models of underground structures near tall buildings," Soil Dynamics and Earthquake Engineering, vol. 86, pp. 89-105, 2016.

[41] L. T. Zhan, X. C. Liu, P. Tai, and Y. M. Chen, "Centrifugal modelling of rainfall-induced slope failure in silty soils and validation of intensity-duration curves," Chinese Journal of Geotechnical Engineering, vol. 36, no. 10, pp. 1784-1790, 2014.

[42] H. S. Pan, T. B. Li, B. Y. Wu, Y. Ren, and T. Song, "Centrifugal model tests on large-scale landslide with broken-line slip surface under rainfall," Chinese Journal of Geotechnical Engineering, vol. 38, no. 4, pp. 696-704, 2016.

[43] J. Y. Qian, G. Zhang, and J. M. Zhang, "Development of rainfall simulation system for centrifugal model tests," Chinese Journal of Geotechnical Engineering, vol. 32, no. 6, pp. 838842, 2010.

[44] J. Zhou, L. Yang, L. X. Wang, and J. Zhang, "Centrifugal model tests on debris flow with different particle compositions," Chinese Journal of Geotechnical Engineering, vol. 37, no. 12, pp. 2167-2174, 2015.

[45] H. Tian, L. W. Kong, and B. Li, "Centrifugal modeling tests on stability of deposits slope under rainfall," Rock and Soil Mechanics, vol. 36, no. 11, pp. 3180-3186, 2015.

[46] P. Chambon and J.-F. Corté, "Shallow tunnels in cohesionless soil: stability of tunnel face," Journal of Geotechnical Engineering, vol. 120, no. 7, pp. 1148-1165, 1994. 

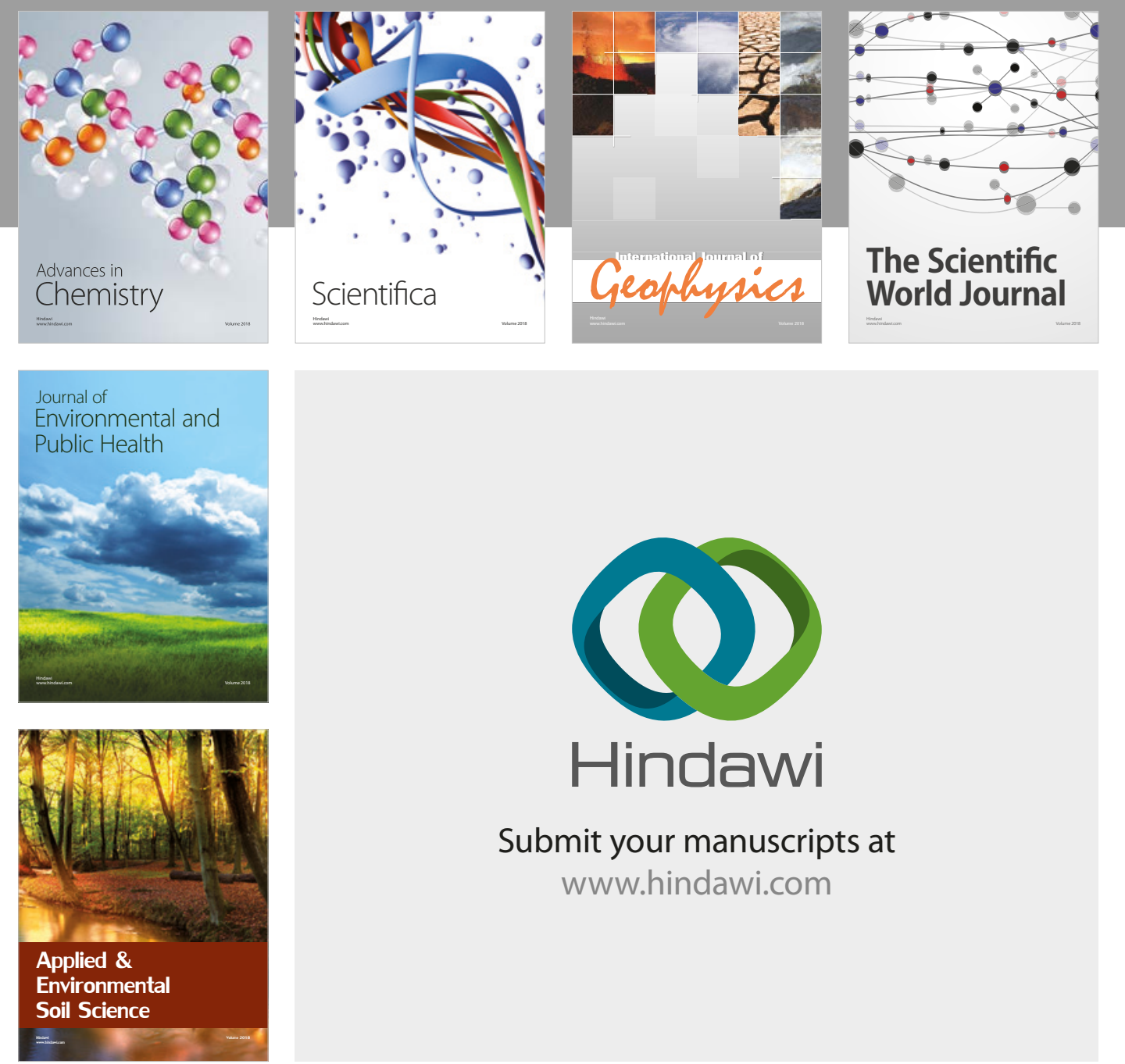

The Scientific

\section{World Journal}
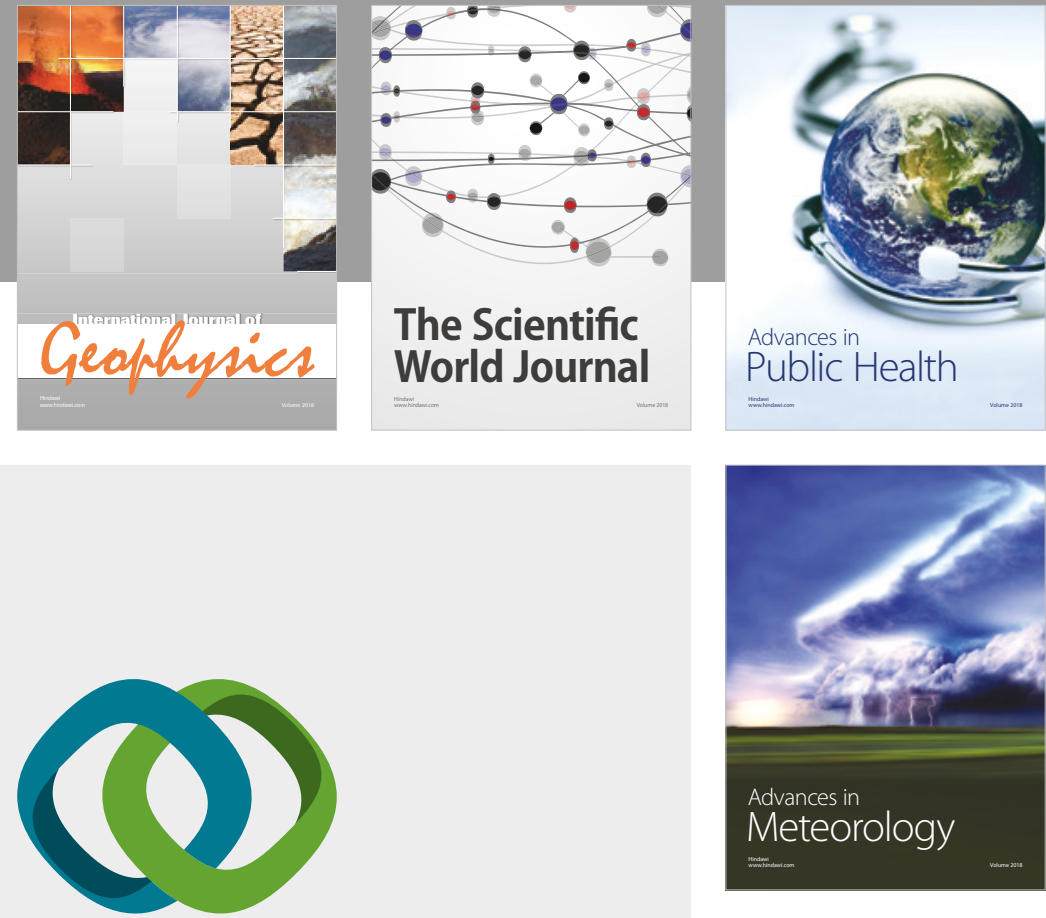

Advan

Public Health

\section{Hindawi}

Submit your manuscripts at

www.hindawi.com
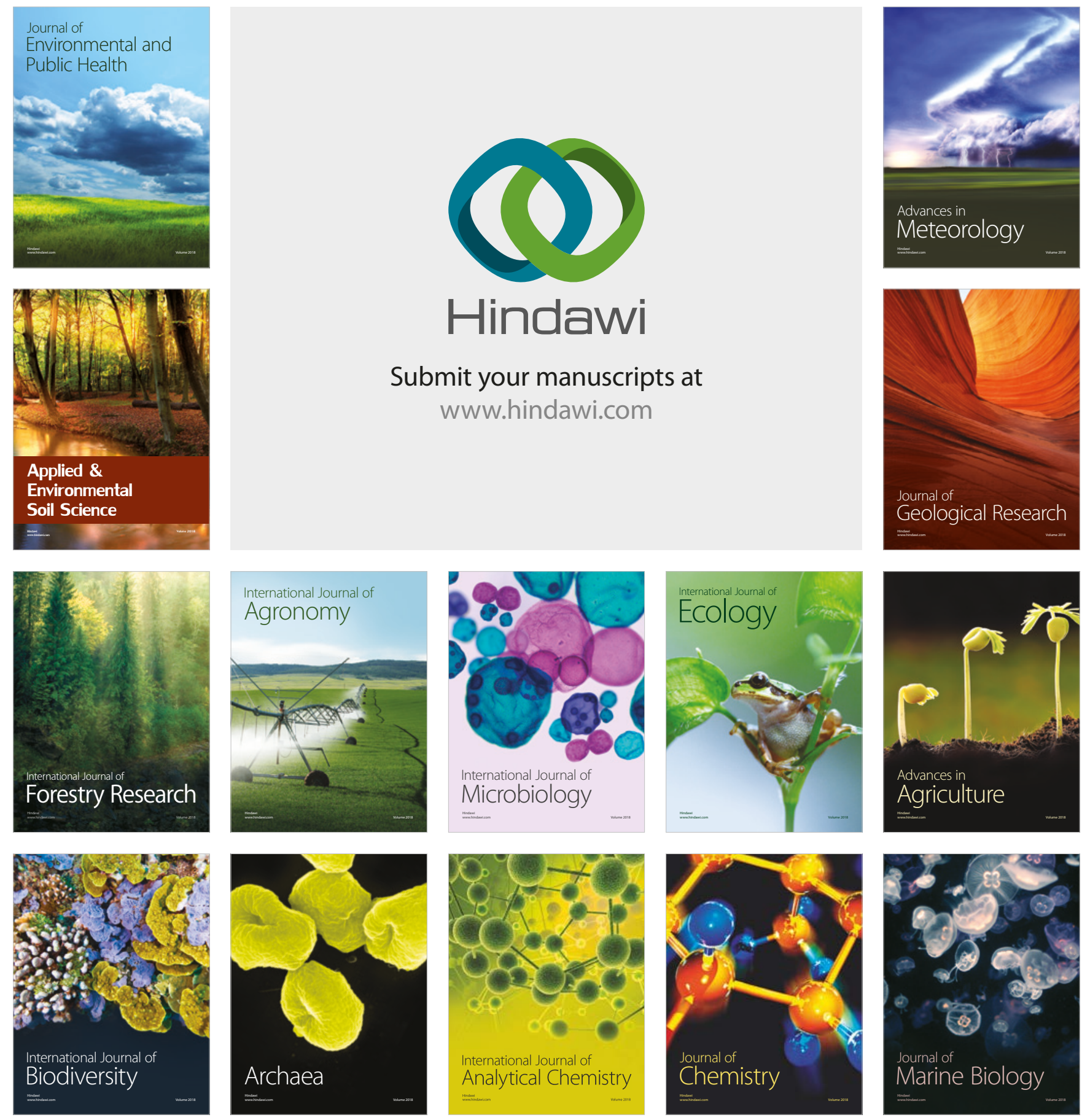